\title{
KİRİŞLERDE BASINÇ DONATISI ORANININ MOMENT-EĞRİLİK İLİŞKİSİNE ETKİSİ
}

\author{
${ }^{1}$ S. Bahadır YÜKSEL (iD), ${ }^{2}$ Rohullah JAMAL (iD) ${ }^{3}$ Saeid FOROUGHİ \\ Konya Teknik Üniversitesi, Mühendislik ve Doğa Bilimleri Fakültesi, İnşaat Mühendisliği Bölümü, Konya, \\ TÜRKIYE \\ 1 ${ }^{1}$ sbyuksel@ktun.edu.tr, ${ }^{2}$ jamal.rohullah@gmail.com, ${ }^{3}$ saeid.foroughi@yahoo.com
}

(Geliş/Received: 29.05.2019; Kabul/Accepted in Revised Form: 05.08.2019)

ÖZ: Bu çalışmada betonarme kirişlerde farklı parametre olarak beton sınıfı, boyuna donatı olarak çekme ve basınç donatısı oranlarının moment-eğrilik davranışına etkisi araştırılmıştır. Parametrelerin değerleri değiştirilerek sayısal bir çalışma yapılmıştır. Bu amaçla, 66 adet farklı parametrelere sahip dikdörtgen en-kesitli betonarme kiriş tasarlanmıştır. Kirişlerin davranışı, malzemelerin doğrusal olmayan davranışları göz önüne alınarak moment-eğrilik ilişkililerinden elde edilmiştir. Analizlerde kiriş kesitlerinde beton için sargısız beton modeli kullanılmıștır. Analiz sonuçları kullanılarak akma ve kırılma durumunda moment-eğrilik değerleri, eğrilik sünekliği ve rijitlik oranları elde edilmiştir. Analiz sonuçlarından farklı parametrelerden elde edilen verilerin sonuçları çizelgeler halinde sunulmuş ve sonuçlar değerlendirilmiştir. Dikdörtgen en-kesitli kirişlerin davranışı, eğrilik sünekliği, rijitlik oranları, kirişlerin akma ve kırılma momentlerinin değerlerinden yararlanarak yorumlanmıştır. Betonarme kiriş elemanlarında basınç donatısı oranının artması ile akma momenti, kırılma momenti ve maksimum eğrilik değerleri artmakta fakat akma eğrilik değerleri azalmaktadır. Betonarme kiriş elemanlarında basınç donatı oranının artması ile elemanların süneklikleri ve rijitlikleri artırmaktadır.

Anahtar Kelimeler: Moment-eğrilik, akma momenti, kırılma momenti, doğrusal olmayan davranış, sargısız beton, eğrilik sünekliği.

\section{Effect of Compression Reinforcement Ratio of Beams on the Moment Curvature Relationships}

\begin{abstract}
In this study, the effect of different parameters like concrete class, longitudinal tensile and compression reinforcement ratios on the moment-curvature behavior of reinforced concrete beams was investigated. A numerical study was performed by changing the values of the parameters. For this purpose, 66 rectangular cross-section reinforced concrete beams with different parameters were designed. The behavior of the beams was obtained from the moment-curvature relationship by considering the nonlinear behavior of the materials. Unconfined concrete model was used for the beam sections in the analysis. Moment-curvature values in the case of yield and ultimate stages, curvature ductility values and stiffness ratios were obtained by using analysis results. The results obtained from the analysis by using different parameters were presented in tables and the results were evaluated. The behavior of the rectangular cross-section beams was interpreted by using the curvature ductility, stiffness ratios, yield and ultimate moments. With the increase in the ratio of compression reinforcement in the reinforced concrete beam elements, yield moment, ultimate moment and maximum curvature values are increased but yield curvature values decrease. With the increase in the ratio of compression reinforcement in the reinforced concrete beam elements, the ductility and stiffness of elements are increased.
\end{abstract}

Key Words: Moment curvature, yield moment, ultimate moment, nonlinear behavior, unconfined concrete, curvature ductility. 


\section{GİRIŞ (INTRODUCTION)}

Betonarme yapı elemanlarının davranışını, elemana ait kesit davranışı belirlemektedir. Kesit davranışı, kesitte kullanılan malzeme, kesitin geometrisi ve kesite etki eden yüklemelere bağlıdır. Eğilme etkisi altındaki bir kesitin davranışı ise en sağlıklı biçimde moment eğrilik ilişkisinden belirlenebilir (Canbay ve diğ., 2010). Kesitin rijitlik ve dayanımının nasıl değiştiği, kesit davranışının süneklik durumu gibi olaylar yine moment-eğrilik ilişkisi üzerinden izlenebilir (Ersoy ve Özcebe, 2012). Yapıların depreme karşı dayanıklı olabilmesi için, yapı elemanlarının yeterli dayanımlarının yanında bu dayanımlarını sürdürebilmeleri için elemanların sünek olmaları gerekmektedir. Betonarme kiriş davranışının kavranabilmesi, kesit davranışının iyi bilinmesi ile mümkündür. Kesit davranışı ise, en sağlıklı biçimde moment-eğrilik ilişkisi üzerinden elde edilir (Çağlar ve diğ., 2014).

Betonarme kirişlerin doğrusal olmayan davranışına etki eden faktörler; çekme ve basınç donatısı oranı, enine donatının çapı, aralığı ve betonun basınç dayanımıdır. Farklı parametrelerde eşit en-kesit alanına sahip dikdörtgen betonarme kiriş kesit modelleri tasarlanmış ve bu modellerin davranışına; beton sınıfının, çekme ve basınç donatısı oranlarının moment-eğrilik ilişkisine olan etkisi araştırılmıştır. İncelenen parametrelerin davranışa etkileri, akma ve kırılma durumunda moment ve eğrilik değerleri, eğrilik sünekliği ve rijitlik değerleri üzerinden değerlendirilmiştir. Farklı parametrelerde tasarlanan dikdörtgen en-kesitli betonarme kiriş modelleri için çizilen moment-eğrilik eğrileri karşılaştırarak yorumlanmıştır. Betonarme elemanların doğrusal olmayan davranışları dikkate alınarak analizler SAP2000 (Ver.20.2.0) programında gerçekleştirilmiştir. Betonarme kiriş kesit hesabı ve tasarımı yapılırken dikkat edilmesi gereken en önemli husus, elde edilen kesitteki donatı oranının, dengeli orandan küçük olmasını sağlamaktır. Bu koşul yönetmeliklerce zorunlu olduğu için bu çalışmada TS500 (2000)'de verilen sınır değerler dikkate alınmıştır. TS500 (2000)'de betonarme kirişlerde sünek davranışın sağlanabilmesi için, donatı oranı Denklem (2 ve 3) ile sınırlandırılmıştır.

$\rho_{b}=0.85 k_{1}\left(\frac{f_{c d}}{f_{y d}}\right)\left(\frac{600}{600+f_{y d}}\right)$

$\rho_{\max }=0.85 \rho_{b}$

$\left(\rho-\rho^{\prime}\right) \leq \rho_{\max }, \quad \rho \leq \rho_{\max } ; 0.02$

Sabit geometride, farklı beton sınıfı, boyuna donatı olarak sabit çekme ve farklı basınç donatı oranlarına sahip toplam 66 adet betonarme kiriş modeli tasarlanmıştır. Betonarme kiriş modellerinin tasarımında Türkiye Bina Deprem Yönetmeliği (TBDY, 2018) ve Betonarme Yapıların Tasarım ve Yapım Kuralları (TS500, 2000)'de verilen hükümler dikkate alınmıştır. Farklı parametrelerde tasarlanan betonarme kiriş modellerinde çekme donatısı oranı olarak; $\rho_{\max }=0.85 \rho_{b}$ ve basınç donatı oranı olarak; $\rho_{s}^{\prime}=0.0,0.1 \rho_{\max }, 0.2 \rho_{\max }, 0.3 \rho_{\max }, 0.4 \rho_{\max }, 0.5 \rho_{\max }, 0.6 \rho_{\max }, 0.7 \rho_{\max }, 0.8 \rho_{\max }, 0.9 \rho_{\max }$ ve $\rho_{\max }$ değerleri dikkate alınmıştır. Betonarme kiriş modellerinde C25, C30, C35, C40, C45 ve C50 olarak altı farklı beton sınıfı dikkate alınmıştır. Kiriş modellerinde her beton sınıfı için çekme donatısı oranı $\rho_{\max }=0.85 \rho_{b}$ olacak şekilde sabit tutulmuş basınç donatısı oranları değiştirilerek kesitlerin momenteğrilik ilişkisi araştırılmışır. İncelenen parametrelerin davranışa etkileri, eğrilik sünekliği, rijitlik oranları ve kiriş taşıma gücü momentleri üzerinden değerlendirilmiş ve karşılaştırarak yorumlanmıştır.

Betonarme kiriş kesitleri için SAP2000 programında malzeme modelleri tanımlanmıştır. SAP2000 programında tanımlanan beton ve donatı çeliği için hesaplarda ve malzeme modellerinde kullanılan parametreler Çizelge 1'de özetlenmiştir. Kirişlerde eksenel yükün maksimum değeri $N=0.10 \times A_{c} \times f_{c}$ olacak şekilde sınırlandırılmıştır (TBDY, 2018). Betonarme kirişlerin analizlerinde eksenel yükün değeri $\mathrm{N}=0$ olarak alınmıştır. Betonarme kesitlerde eksenel yükün olmadığı durumlarda sargı donatısının etkisi azalmaktadır. Bundan dolayı analizlerde beton modeli olarak Mander sargisız beton modeli (Mander ve diğ., 1988) kullanılmıştır. 


\section{MATERYAL ve METOT (MATERIALS and METHODS)}

Betonarme kesitlerin moment-eğrilik ilişkilerini etkileyen ve tasarım aşamasında birer parametre olarak düşünülen, beton basınç dayanımı, çekme donatısı oranı ve basınç donatısı oranı gibi faktörlerin moment-eğrilik davranışına olan etkisinin incelenmesi bu çalışmanın amacını oluşturmaktadır. Bu amaçla kiriş kesitlerin moment-eğrilik ilişkisi araştırılarak akma ve kırılma durumunda moment ve eğrilik değerleri, eğrilik sünekliği ve rijitlik değerleri elde edilmiştir. Elde edilen moment-eğrilik ilişkileri farklı parametrelere göre karşılaştırmalı olarak grafikler halinde sunulmuştur. Moment-eğrilik ilişkilerinden elde edilen değerler çizelgeler halinde karşılaştırmalı olarak özetlenmiştir. Tasarım parametrelerinin incelenmesi için analizlerde dikkate alınan kiriş kesiti $250 \mathrm{~mm} \times 500 \mathrm{~mm}$ boyutlarında olup Şekil 1'de kesit geometrisi ve donatı yerleşim planı verilmiştir. Şekil 1'de $A_{s}$; çekme donatısı alanını, $A_{s}^{\prime}$; basınç donatısı alanını ifade etmektedir. Beton basınç dayanımı ile bağımlı olarak incelenen parametre; sabit çekme donatısı oranına göre basınç donatısı oranıdır. Bu amaçla 66 adet farklı betonarme kiriş modelinin moment-eğrilik analizi yapılmıştır.

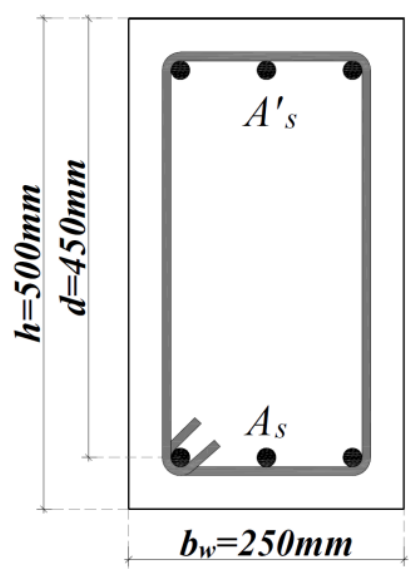

Şekil 1. Tasarlanan kiriş modellerinin en-kesit detayları

Figure 1. Cross-section details of designed beam models

Betonarme kiriş kesit hesabı ve tasarımı yapılırken dikkat edilmesi gereken en önemli husus, elde edilen kesitteki donatı oranının, yönetmeliklerce öngörülen maksimum donatı oranından küçük olmasını sağlamaktır. Bu koşul yönetmeliklerce zorunlu olduğu için bu çalışmada TS500 (2000)'e göre Denklem (2 ve 3)'te verilen sınır değerler dikkate alınmıştır. Bu çalışmada betonarme kirişlerin eğrilik sünekliği gibi parametrelerinin araştırılması için sabit çekme donatısı oranı dikkate alınmıştır. Hesaplarda çekme donatısı oranı $\left(\rho_{s}=\rho_{\max }=0.85 \rho_{b}\right)$ tüm kiriş modellerinde sabit alınmıştır. Betonarme kiriş modellerinde basınç donatısı oranları $\left(\rho_{s}^{\prime}=0.0,0.1 \rho_{\max }, 0.2 \rho_{\max }, 0.3 \rho_{\max }, 0.4 \rho_{\max }\right.$, $0.5 \rho_{\max }, 0.6 \rho_{\max }, 0.7 \rho_{\max }, 0.8 \rho_{\max }, 0.9 \rho_{\max }$ ve $\rho_{\max }$ ) değiştirilerek kiriş elemanlarının moment-eğrilik ilişkileri incelenmiştir. Beton basınç dayanımının kiriş davranışı üzerinde etkisini araştırmak için farklı beton basınç dayanımları (C25, C30, C35, C40, C45, C50) dikkate alınmıştır. Çizelge 2, 3, 4, 5, 6 ve 7' den görüleceği gibi kirişlerde sabit beton sınıfı ve çekme donatısı oranı için basınç donatısı oranı sıfırdan maksimum donatı oranına kadar 11 farklı değer verilerek değiştirilmiştir.

Betonarme kesitlerde süneklik, kesitin dayanımında önemli bir azalma olmadan yapabileceği doğrusal ötesi deformasyon kapasitesi olarak tanımlanır. Sayısal olarak ise eğrilik sünekliği $(\mu)$, eğrilik süneklik oranı $\left(\mu_{o}\right)$ olacak şekilde Denklem (4 ve 10) ile ifade edilir. Eğrilik süneklik katsayısı, kesitin kırılma anında yaptığı eğriliğin $\left(k_{u}\right)$, çekme donatısının aktığı anda kesitte oluşan eğriliğe $\left(k_{y}\right)$ oranıdır.

$\mu=\frac{k_{u}}{k_{y}}$ 
Moment-eğrilik grafiğinin ilk doğrunun eğimi, çatlamış kesite ait etkin eğilme rijitliğine $(E I)$ karşılık gelmektedir (Çağlar ve diğ., 2014). Betonarme kirişlerin etkin eğilme rijitliği Denklem (5) ile hesaplanmıştır. Denklem (5)'te $M_{y}$ ve $k_{y}$ sırasıyla akma momenti ve akma eğriliğidir.

$E I_{e}=\frac{\mathrm{M}_{\mathrm{y}}}{\mathrm{k}_{\mathrm{y}}}$

Betonarme kirişlerin kesit geometrisi $(b$ ve $h)$ ve betonun elastisite modülüne $\left(E_{c}\right)$ göre çatlamamış kesit rijitlikleri (EI) Denklem (6 ve 7) ile hesaplanmıştır. Farklı beton sınıfları için (TS-500, 2000)'de verilen beton karakteristik basınç dayanımlarına $\left(f_{c k}\right)$ göre beton elastisite modülleri $\left(E_{c}\right)$ hesaplanmıştır. $I$; betonarme kirişlerin brüt atalet momentidir ve kesit geometrisine göre hesaplanmaktadır.

$E_{c}=3250+\sqrt{f_{c k}}+14000$

$I=\frac{b h^{3}}{12}$

Betonarme kirişler için hesaplanan etkin eğilme rijitliği ve çatlamamış kesit eğilme rijitliklerinden etkin rijitlik çarpanları $\left(k_{e}\right)$ Denklem (8)'den hesaplanmıştır.

$k_{e}=\frac{E I_{e}}{E I}$

Betonarme kirişlerde moment-eğrilik ilişkilerinden akma ve kırılma durumları için moment $\left(M_{y}, M_{u}\right)$ ve eğrilik $\left(K_{y}, K_{u}\right)$ değerleri, akma ve kırılma eğriliklerinden eğrilik süneklikleri $(\mu)$, akma momentleri ve akma eğriliklerinden etkin eğilme rijitlikleri $\left(E I_{e}\right)$ ve etkin rijitlik çarpanları $\left(k_{e}\right)$ hesaplanmıştır.

Denklem (5) ile hesaplanan etkin eğilme rijitline göre betonarme kirişlerin farklı parametreler (basınç donatı oranı ve beton basınç dayanımı) için etkin eğilme rijitlik oranları $\left(E I_{O}\right)$ Denklem (9)'a göre hesaplanmıştır.

$E I_{e-1}$; maksimum çekme donatısı oranına sahip basınç donatısı olmayan betonarme kirişlerin $\left(\rho_{s}=\rho_{\max }=0.85 \rho_{b}, \rho_{s}^{\prime}=0.0\right)$ etkin eğilme rijitliği değeridir. $E I_{e-i} ;$ maksimum çekme donatısı oranı $\left(\rho_{s}=\rho_{\max }=0,85 \rho_{b}\right)$ ve farklı basınç donatısı oranına sahip $\left(\rho_{s}^{\prime}=0.0,0.1 \rho_{\max }, 0.2 \rho_{\max }, 0.3 \rho_{\max }, 0.4 \rho_{\max }\right.$, $0.5 \rho_{\max }, 0.6 \rho_{\max }, 0.7 \rho_{\max }, 0.8 \rho_{\max }, 0.9 \rho_{\max }$ ve $\left.\rho_{\max }\right) 11$ farklı kiriş modelinin etkin eğilme rijitliğ değerleridir.

$E I_{O}=\frac{E I_{e-i}}{E I_{e-1}}$

Denklem (4) ile hesaplanan eğrilik süneklik katsayısına göre betonarme kirişlerin farklı parametreler (basınç donatı oranı ve beton basınç dayanımı) için eğrilik süneklik oranları $\left(\mu_{O}\right)$ Denklem (10)'a göre hesaplanmıştır. $\mu_{O-1}$; maksimum çekme donatısı oranına sahip basınç donatısı olmayan betonarme kirişlerin $\left(\rho_{s}=\rho_{\max }=0,85 \rho_{b}, \rho_{s}^{\prime}=0.0\right)$ eğrilik süneklik değeridir. $\mu_{O-i}$; maksimum çekme donatısı oranı $\left(\rho_{s}=\rho_{\max }=0.85 \rho_{b}\right)$ ve farklı basınç donatısı oranına sahip $\left(\rho_{s}^{\prime}=0.0,0.1 \rho_{\max }, 0.2 \rho_{\max }, 0.3 \rho_{\max }, 0.4 \rho_{\max }\right.$, $0.5 \rho_{\max }, 0.6 \rho_{\max }, 0.7 \rho_{\max }, 0.8 \rho_{\max }, 0.9 \rho_{\max }$ ve $\left.\rho_{\max }\right) 11$ farklı kiriş modelinin eğrilik süneklik değerleridir.

$\mu_{O}=\frac{\mu_{O-i}}{\mu_{O-1}}$

Betonarme kiriş kesitlerinde moment-eğrilik ilişkilerinden elde edilen akma ve kırılma durumları için moment $\left(M_{y}, M_{u}\right)$ değerlerine göre farklı parametrelere sahip betonarme kirişler için $M_{y i} / M_{y 1}$ ve $M_{u i} / M_{u 1}$ oran değerleri hesaplanmıştır. $M_{y 1}$ ve $M_{u 1}$; maksimum çekme donatısı oranına sahip basınç 
donatısı olmayan betonarme kirişlerin $\left(\rho_{s}=\rho_{\max }=0.85 \rho_{b}, \quad \rho_{s}^{\prime}=0.0\right)$ akma ve kırılma momentleridir. $M_{y i}$ ve $M_{u i}$; sabit beton basınç dayanımı ve maksimum çekme donatısı oranı $\left(\rho_{s}=\rho_{\max }=\right.$ $\left.0,85 \rho_{b}\right)$ ve farklı basınç donatısı oranına sahip $\left(\rho_{s}^{\prime}=0.0,0.1 \rho_{\max }, 0.2 \rho_{\max }, 0.3 \rho_{\max }, 0.4 \rho_{\max }, 0.5 \rho_{\max }\right.$, $0.6 \rho_{\max }, 0.7 \rho_{\max }, 0.8 \rho_{\max }, 0.9 \rho_{\max }$ ve $\left.\rho_{\max }\right) 11$ farklı kirişin akma ve kırılma momentleridir.

Çizelge 1. Malzeme modellerinde kullanılan parametreler (TBDY, 2018)

Table 1. Material parameters used in the model

\begin{tabular}{|c|l|c|}
\hline Malzeme & \multicolumn{1}{|c|}{ Parametre } & Değer \\
\hline \multirow{2}{*}{$\begin{array}{c}\text { Beton } \\
\text { Sınıfı: C25- } \\
\text { C50 }\end{array}$} & $\begin{array}{l}\text { Sargısız betonun maksimum gerilmeye ulaştı̆̆ birim şekil değiştirme } \\
\text { değeri }\left(\varepsilon_{c o}\right)\end{array}$ & 0.002 \\
\cline { 2 - 3 } & Sargısız betonun nihai birim şekil-değiştirmesi $\left(\varepsilon_{c u}\right)$ & 0.0035 \\
\cline { 2 - 3 } & Karakteristik beton basıç dayanımı $\left(f_{c k}\right)$ & $25-50 \mathrm{MPa}$ \\
\hline \multirow{4}{*}{$\begin{array}{c}\text { Donat1 } \\
\text { Çeliği: S420 }\end{array}$} & Donatı çeliğinin akma birim şekil değiştirmesi $\left(\varepsilon_{s y}\right)$ & 0.0021 \\
\cline { 2 - 3 } & Donatı çeliğinin pekleşme birim şekil değiştirmesi $\left(\varepsilon_{s p}\right)$ & 0.008 \\
\cline { 2 - 3 } & Donatı çeliğinin kopma birim şekil değiştirmesi $\left(\varepsilon_{s u}\right)$ & 0.08 \\
\cline { 2 - 3 } & Donatı çeliğinin karakteristik akma dayanımı $\left(f_{y k}\right)$ & $420 \mathrm{MPa}$ \\
\cline { 2 - 3 } & Donatı çeliğinin karakteristik kopma dayanımı $\left(f_{s u}\right)$ & $550 \mathrm{MPa}$ \\
\hline
\end{tabular}

Çizelge 2. Tip-1 olarak tasarlanan kiriş modellerine ait parametreler.

Table 2. Parameters of models designed as type-1

\begin{tabular}{|c|c|c|c|c|c|c|c|c|}
\hline $\begin{array}{l}\text { Kesit } \\
\text { Grubu }\end{array}$ & $\begin{array}{c}\text { Kesit } \\
\text { No }\end{array}$ & Beton Sinifi & $\begin{array}{c}A_{s} \\
\left(\boldsymbol{m} \boldsymbol{m}^{2}\right)\end{array}$ & $\begin{array}{c}A_{s}^{\prime} \\
\left(\boldsymbol{m} \boldsymbol{m}^{2}\right)\end{array}$ & $\rho_{b}$ & $\rho$ & $\rho^{\prime}$ & $\frac{\rho-\rho^{\prime}}{\rho_{b}}$ \\
\hline \multirow{11}{*}{ Tip-1 } & B1-0 & \multirow{11}{*}{$\mathrm{C} 25$} & \multirow{11}{*}{1991.3} & 0.0 & \multirow{11}{*}{0.0208} & \multirow{11}{*}{0.0177} & 0.0000 & 0.85 \\
\hline & B1-1 & & & 199.1 & & & 0.0018 & 0.77 \\
\hline & B1-2 & & & 398.3 & & & 0.0035 & 0.68 \\
\hline & B1-3 & & & 597.4 & & & 0.0053 & 0.60 \\
\hline & B1-4 & & & 796.5 & & & 0.0071 & 0.51 \\
\hline & B1-5 & & & 995.6 & & & 0.0089 & 0.43 \\
\hline & B1-6 & & & 1194.8 & & & 0.0106 & 0.34 \\
\hline & B1-7 & & & 1393.9 & & & 0.0124 & 0.26 \\
\hline & B1-8 & & & 1593.0 & & & 0.0142 & 0.17 \\
\hline & B1-9 & & & 1792.1 & & & 0.0159 & 0.09 \\
\hline & B1-10 & & & 1991.3 & & & 0.0177 & 0.00 \\
\hline
\end{tabular}

Çizelge 3. Tip-2 olarak tasarlanan kiriş modellerine ait parametreler.

Table 3. Parameters of models designed as type-2

\begin{tabular}{|c|cccccccc|}
\hline $\begin{array}{c}\text { Kesit } \\
\text { Grubu }\end{array}$ & Kesit No & Beton Sinifi & $\begin{array}{c}\boldsymbol{A}_{\boldsymbol{s}} \\
\left(\mathbf{m m}^{\mathbf{2}}\right)\end{array}$ & $\begin{array}{c}\boldsymbol{A}_{\boldsymbol{s}}^{\prime} \\
\left(\boldsymbol{m m}^{\mathbf{2}}\right)\end{array}$ & $\boldsymbol{\rho}_{\boldsymbol{b}}$ & $\boldsymbol{\rho}$ & $\boldsymbol{\rho}^{\prime}$ & $\frac{\boldsymbol{\rho}_{-\boldsymbol{\rho}^{\prime}}}{\boldsymbol{\rho}_{\boldsymbol{b}}}$ \\
\hline & B2-0 & & & 0.0 & & 0.0000 & 0.85 \\
& B2-1 & & & 226.1 & & & 0.0020 & 0.77 \\
& B2-2 & & & 452.3 & & & 0.0040 & 0.68 \\
& B2-3 & & & 678.4 & & & 0.0060 & 0.60 \\
& B2-4 & & & 904.5 & & & 0.0080 & 0.51 \\
Tip-2 & B2-5 & C30 & 2261.3 & 1130.6 & 0.0236 & 0.0201 & 0.0101 & 0.43 \\
& B2-6 & & & 1356.8 & & & 0.0121 & 0.34 \\
& B2-7 & & & 1582.9 & & & 0.0141 & 0.26 \\
& B2-8 & & & 1809.0 & & & 0.0161 & 0.17 \\
& B2-9 & & & 2035.1 & & & 0.0181 & 0.08 \\
& B2-10 & & & 2261.3 & & 0.0201 & 0.00 \\
\hline
\end{tabular}


Çizelge 4. Tip-3 olarak tasarlanan kiriş modellerine ait parametreler.

Table 4. Parameters of models designed as type-3

\begin{tabular}{|c|c|c|c|c|c|c|c|c|}
\hline $\begin{array}{c}\text { Kesit } \\
\text { Grubu }\end{array}$ & Kesit No & Beton Sinifi & $\begin{array}{c}A_{s} \\
\left(\boldsymbol{m m ^ { 2 } )}\right.\end{array}$ & $\begin{array}{c}A_{s}^{\prime} \\
\left(\boldsymbol{m m ^ { 2 } )}\right) \\
\end{array}$ & $\rho_{b}$ & $\rho$ & $\rho^{\prime}$ & $\frac{\rho-\rho^{\prime}}{\rho_{b}}$ \\
\hline \multirow{11}{*}{ Tip-3 } & B3-0 & \multirow{11}{*}{ C35 } & \multirow{11}{*}{2508.8} & 0.0 & \multirow{11}{*}{0.0262} & \multirow{11}{*}{0.0223} & 0.0000 & 0.85 \\
\hline & B3-1 & & & 250.9 & & & 0.0022 & 0.77 \\
\hline & B3-2 & & & 501.8 & & & 0.0045 & 0.68 \\
\hline & B3-3 & & & 752.6 & & & 0.0067 & 0.60 \\
\hline & B3-4 & & & 1003.5 & & & 0.0089 & 0.51 \\
\hline & B3-5 & & & 1254.4 & & & 0.0112 & 0.43 \\
\hline & B3-6 & & & 1505.3 & & & 0.0134 & 0.34 \\
\hline & B3-7 & & & 1756.1 & & & 0.0156 & 0.26 \\
\hline & B3-8 & & & 2007.0 & & & 0.0178 & 0.17 \\
\hline & B3-9 & & & 2257.9 & & & 0.0201 & 0.08 \\
\hline & B3-10 & & & 2508.8 & & & 0.0223 & 0.00 \\
\hline
\end{tabular}

Çizelge 5. Tip-4 olarak tasarlanan kiriş modellerine ait parametreler.

Table 5. Parameters of models designed as type-4

\begin{tabular}{|c|cccccccc|}
\hline $\begin{array}{c}\text { Kesit } \\
\text { Grubu }\end{array}$ & $\begin{array}{c}\text { Kesit } \\
\text { No }\end{array}$ & Beton Sinifi & $\begin{array}{c}\boldsymbol{A}_{\boldsymbol{s}} \\
\left(\boldsymbol{m m}^{\mathbf{2}}\right)\end{array}$ & $\begin{array}{c}\boldsymbol{A}_{\boldsymbol{s}}^{\prime} \\
\left(\boldsymbol{m m}^{\mathbf{2}}\right)\end{array}$ & $\boldsymbol{\rho}_{\boldsymbol{b}}$ & $\boldsymbol{\rho}$ & $\boldsymbol{\rho}^{\prime}$ & $\frac{\boldsymbol{\rho}-\boldsymbol{\rho}^{\prime}}{\boldsymbol{\rho}_{\boldsymbol{b}}}$ \\
\hline & B4-0 & & & 0.0 & & & 0.0000 & 0.85 \\
& B4-1 & & & 283.5 & & & 0.0025 & 0.77 \\
& B4-2 & & & 567.0 & & & 0.0050 & 0.68 \\
& B4-3 & & & 850.5 & & & 0.0076 & 0.60 \\
& B4-4 & & & 1134.0 & & & 0.0101 & 0.51 \\
Tip-4 & & & & & & & \\
& B4-5 & C40 & 2835 & 1417.5 & 0.0296 & 0.0252 & 0.0126 & 0.43 \\
& B4-6 & & & 1701.0 & & & 0.0151 & 0.34 \\
& B4-7 & & & 1984.5 & & & 0.0176 & 0.26 \\
& B4-8 & & & 2268.0 & & & 0.0202 & 0.17 \\
& B4-9 & & & 2551.5 & & & 0.0227 & 0.08 \\
& B4-10 & & & 2835.0 & & & 0.0252 & 0.00 \\
\hline
\end{tabular}

Çizelge 6. Tip-5 olarak tasarlanan kiriş modellerine ait parametreler.

Table 6. Parameters of models designed as type-5

\begin{tabular}{|c|c|c|c|c|c|c|c|c|}
\hline $\begin{array}{c}\text { Kesit } \\
\text { Grubu }\end{array}$ & Kesit No & Beton Sinifi & $\begin{array}{c}A_{s} \\
\left(\boldsymbol{m m ^ { 2 }}\right) \\
\end{array}$ & $\begin{array}{c}A_{s}^{\prime} \\
\left(\boldsymbol{m m}^{2}\right)\end{array}$ & $\rho_{b}$ & $\rho$ & $\rho^{\prime}$ & $\frac{\rho-\rho^{\prime}}{\rho_{b}}$ \\
\hline \multirow{11}{*}{ Tip-5 } & B5-0 & \multirow{11}{*}{ C45 } & \multirow{11}{*}{3026.3} & 0.0 & \multirow{11}{*}{0.0316} & \multirow{11}{*}{0.0269} & 0.0000 & 0.85 \\
\hline & B5-1 & & & 302.6 & & & 0.0027 & 0.77 \\
\hline & B5-2 & & & 605.3 & & & 0.0054 & 0.68 \\
\hline & B5-3 & & & 907.9 & & & 0.0081 & 0.60 \\
\hline & B5-4 & & & 1210.5 & & & 0.0108 & 0.51 \\
\hline & B5-5 & & & 1513.1 & & & 0.0135 & 0.43 \\
\hline & B5-6 & & & 1815.8 & & & 0.0161 & 0.34 \\
\hline & B5-7 & & & 2118.4 & & & 0.0188 & 0.26 \\
\hline & B5-8 & & & 2421.0 & & & 0.0215 & 0.17 \\
\hline & B5-9 & & & 2723.6 & & & 0.0242 & 0.08 \\
\hline & B5-10 & & & 3026.3 & & & 0.0269 & 0.00 \\
\hline
\end{tabular}


Çizelge 7. Tip-6 olarak tasarlanan kiriş modellerine ait parametreler.

Table 7. Parameters of models designed as type-6

\begin{tabular}{|c|c|c|c|c|c|c|c|c|}
\hline $\begin{array}{c}\text { Kesit } \\
\text { Grubu }\end{array}$ & Kesit No & Beton Sinifi & $\begin{array}{c}A_{s} \\
\left(\boldsymbol{m m ^ { 2 }}\right)\end{array}$ & $\begin{array}{c}A_{s}^{\prime} \\
\left(\boldsymbol{m m ^ { 2 } )}\right.\end{array}$ & $\rho_{b}$ & $\rho$ & $\rho^{\prime}$ & $\frac{\rho-\rho^{\prime}}{\rho_{b}}$ \\
\hline \multirow{11}{*}{ Tip-6 } & B6-0 & \multirow{11}{*}{ C50 } & \multirow{11}{*}{3183.8} & 0.0 & \multirow{11}{*}{0.0333} & \multirow{11}{*}{0.0283} & 0.0000 & 0.85 \\
\hline & B6-1 & & & 318.4 & & & 0.0028 & 0.77 \\
\hline & B6-2 & & & 636.8 & & & 0.0057 & 0.68 \\
\hline & B6-3 & & & 955.1 & & & 0.0085 & 0.60 \\
\hline & B6-4 & & & 1273.5 & & & 0.0113 & 0.51 \\
\hline & B6-5 & & & 1591.9 & & & 0.0142 & 0.43 \\
\hline & B6-6 & & & 1910.3 & & & 0.0170 & 0.34 \\
\hline & B6-7 & & & 2228.6 & & & 0.0198 & 0.26 \\
\hline & B6-8 & & & 2547.0 & & & 0.0226 & 0.17 \\
\hline & B6-9 & & & 2865.4 & & & 0.0255 & 0.09 \\
\hline & B6-10 & & & 3183.8 & & & 0.0283 & 0.00 \\
\hline
\end{tabular}

\section{ANALİTIK ÇALIŞMA (ANALYTICAL STUDY)}

Betonarme kiriş elemanlarının doğrusal olmayan davranışının incelenerek bu davranışı etkileyen parametrelerin araştırması yapılmıştır. Betonarme kiriş elemanlarının davranışı moment-eğrilik ilişkisinden incelenmiştir. Moment-eğrilik ilişkileri ise malzemelerin doğrusal olmayan davranışları dikkate alınarak farklı parametreler için SAP2000 programı ile elde edilmiştir. Betonarme kolon kesitin üç farklı malzeme modelinden oluştuğu düşünülmüştür. SAP2000 programı ile yapılan moment-eğrilik analizlerinde, kabuk betonu için Mander sargısız beton modeli, çekirdek betonu için Mander sargılı beton modeli (Mander ve diğ., 1988) ve donatı çeliği için Çizelge (1)'de verilen pekleşmeli model kullanılmıştır. Analiz sonuçlarından elde edilen moment-eğrilik grafiklerinden farklı modeller ve parametreler için elde edilen sınır değerler $\left(k_{y}, \mathrm{M}_{\mathrm{y}}, k_{\mathrm{u}}, \mathrm{Mu}_{\mathrm{u}}\right)$ çizelgeler halinde özetlenmiştir. Eğrilik sünekliği ise moment-eğrilik ilişkilerinden elde edilen $k_{\mathrm{y}}$ ve $k_{\mathrm{u}}$ değerlerinden faydalanarak Denklem (4)'ten hesaplanmıştır. Analitik çalışmanın kapsamında 66 adet farklı parametrelerde tasarlanan betonarme kiriş modelleri üzerinde analizler ve hesaplamalar yapılarak moment-eğrilik grafikleri karşılaştırmalı olarak verilmiştir. Daha sonra elde edilen ilişkilere göre elde edilen sonuçlar karşılaştırmalı olarak çizelgeler halinde özetlenmiştir. Farklı parametrelere göre incelenen kiriş modelleri için analizlerden elde edilen moment-eğrilik grafikleri Şekil 2, 3, 4, 5, 6 ve 7' de verilmiştir. 


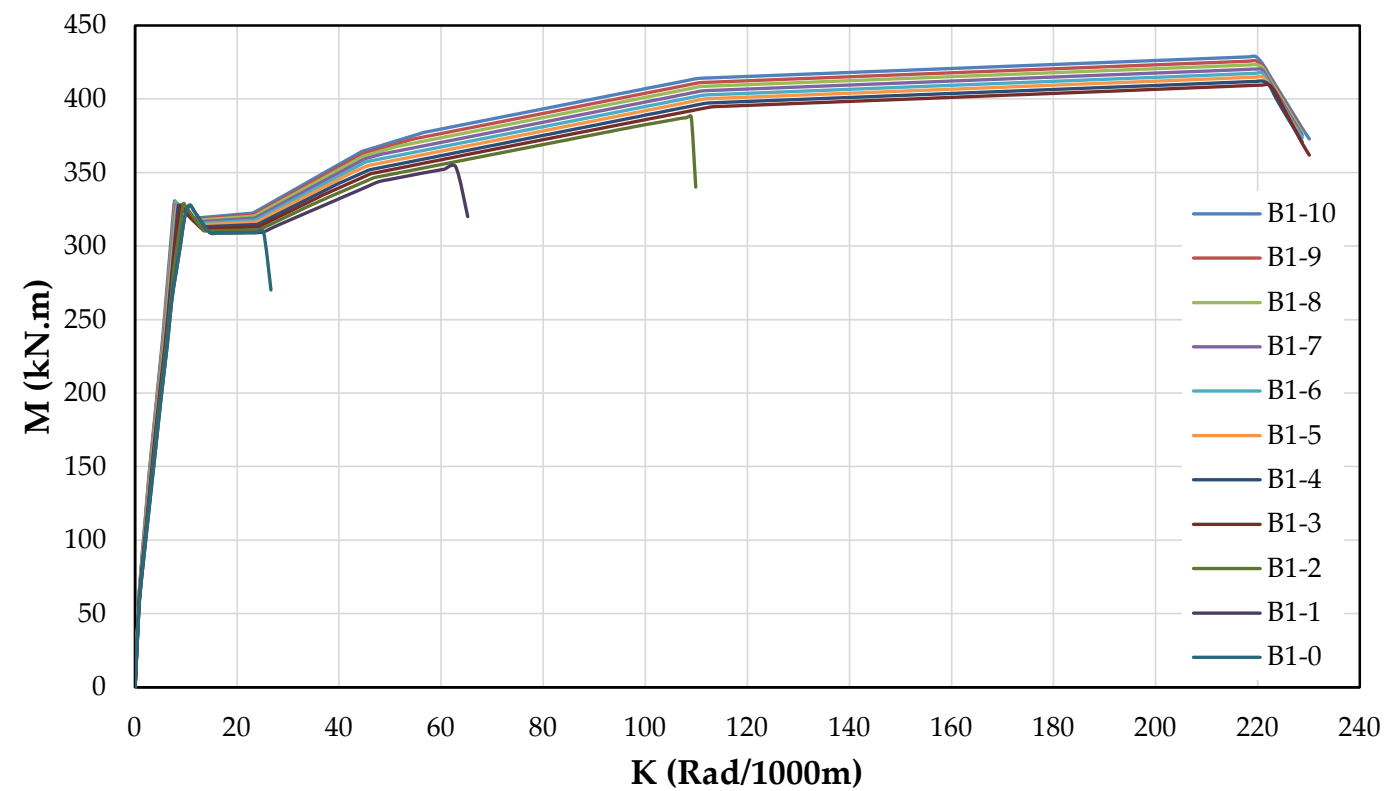

Şekil 2. Tip-1 olarak tasarlanan kiriş modellerine ait karşılaştırmalı moment eğrilik grafikleri. Figure 2. Comparative moment curvature graphs of beam models designed as Type-1

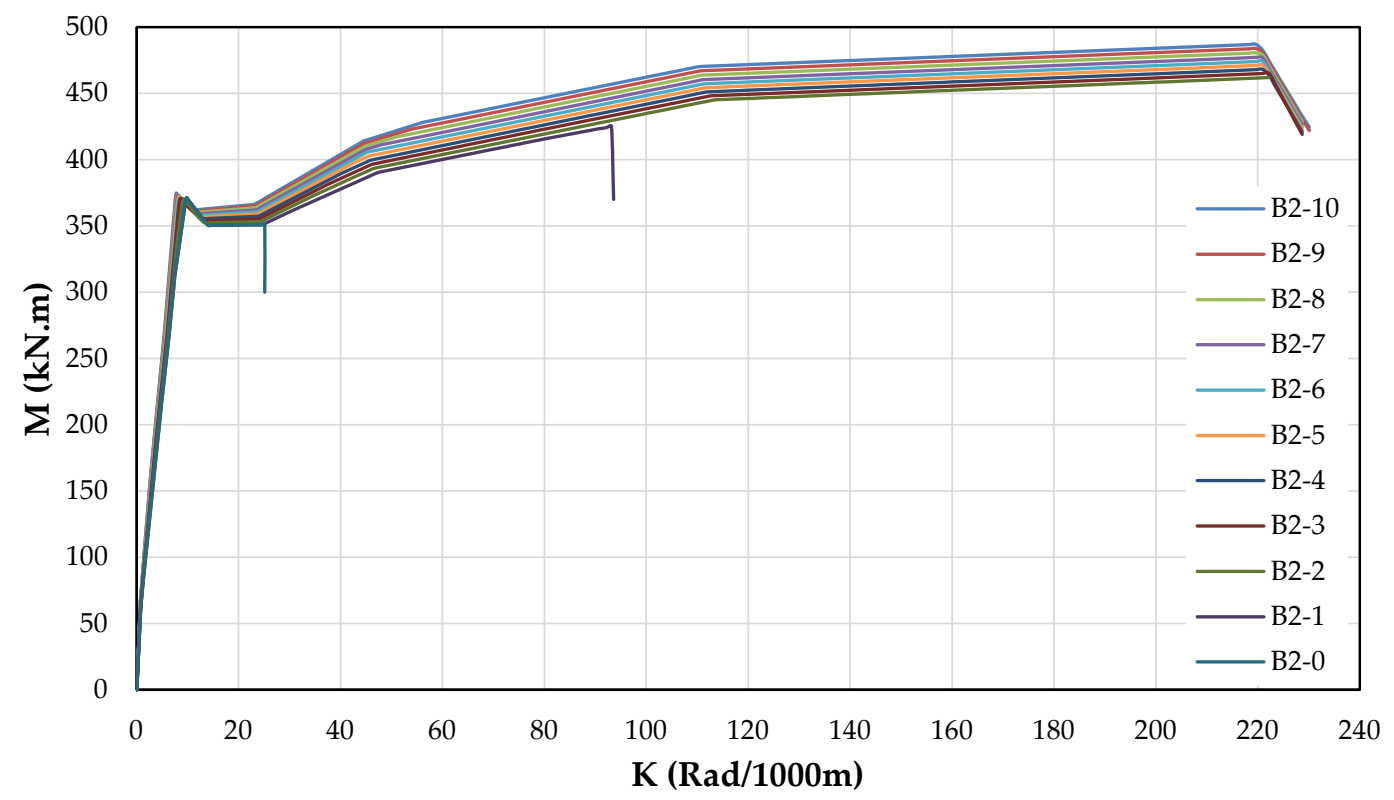

Şekil 3. Tip-2 olarak tasarlanan kiriş modellerine ait karşılaştırmalı moment eğrilik grafikleri. Figure 3. Comparative moment curvature graphs of beam models designed as Type-2 


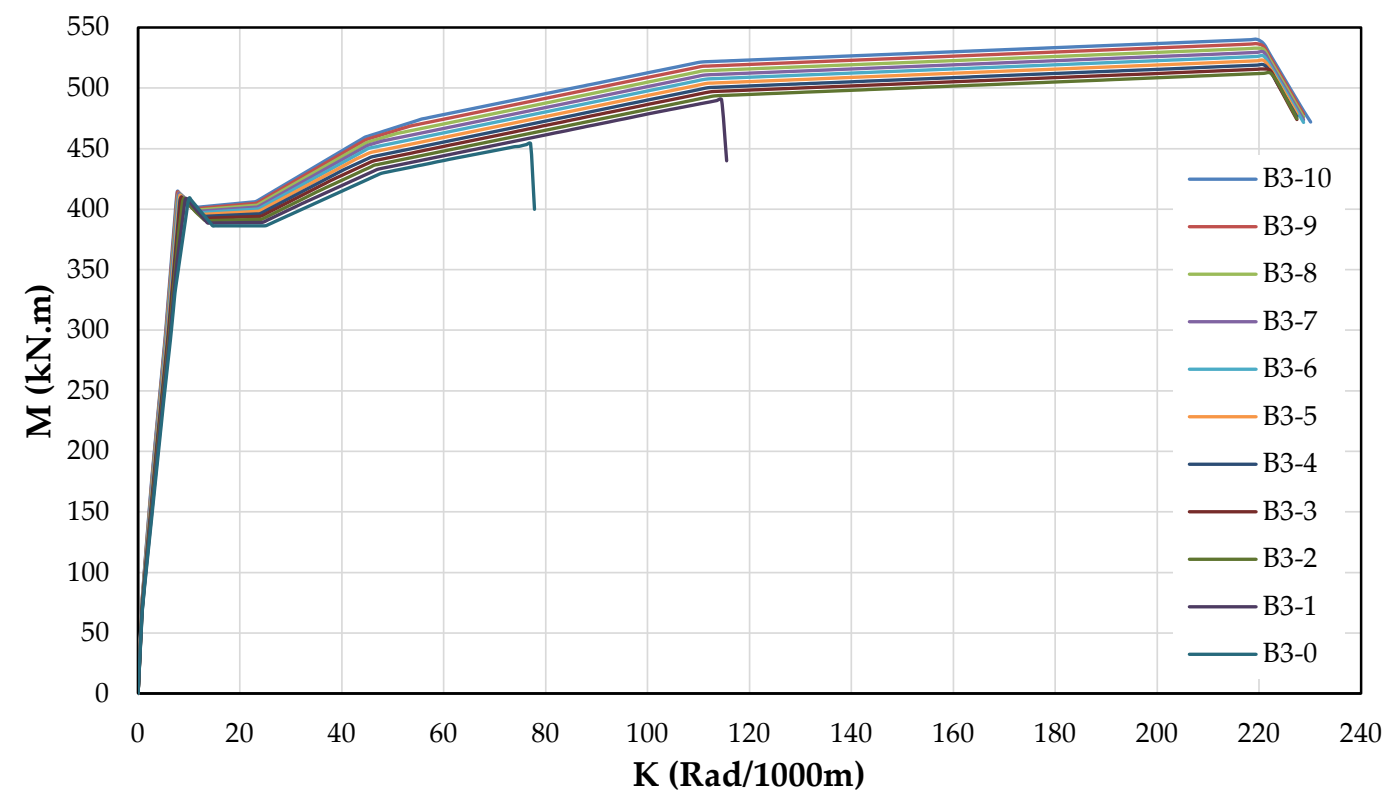

Şekil 4. Tip-3 olarak tasarlanan kiriş modellerine ait karşılaştırmalı moment eğrilik grafikleri. Figure 4. Comparative moment curvature graphs of beam models designed as Type-3

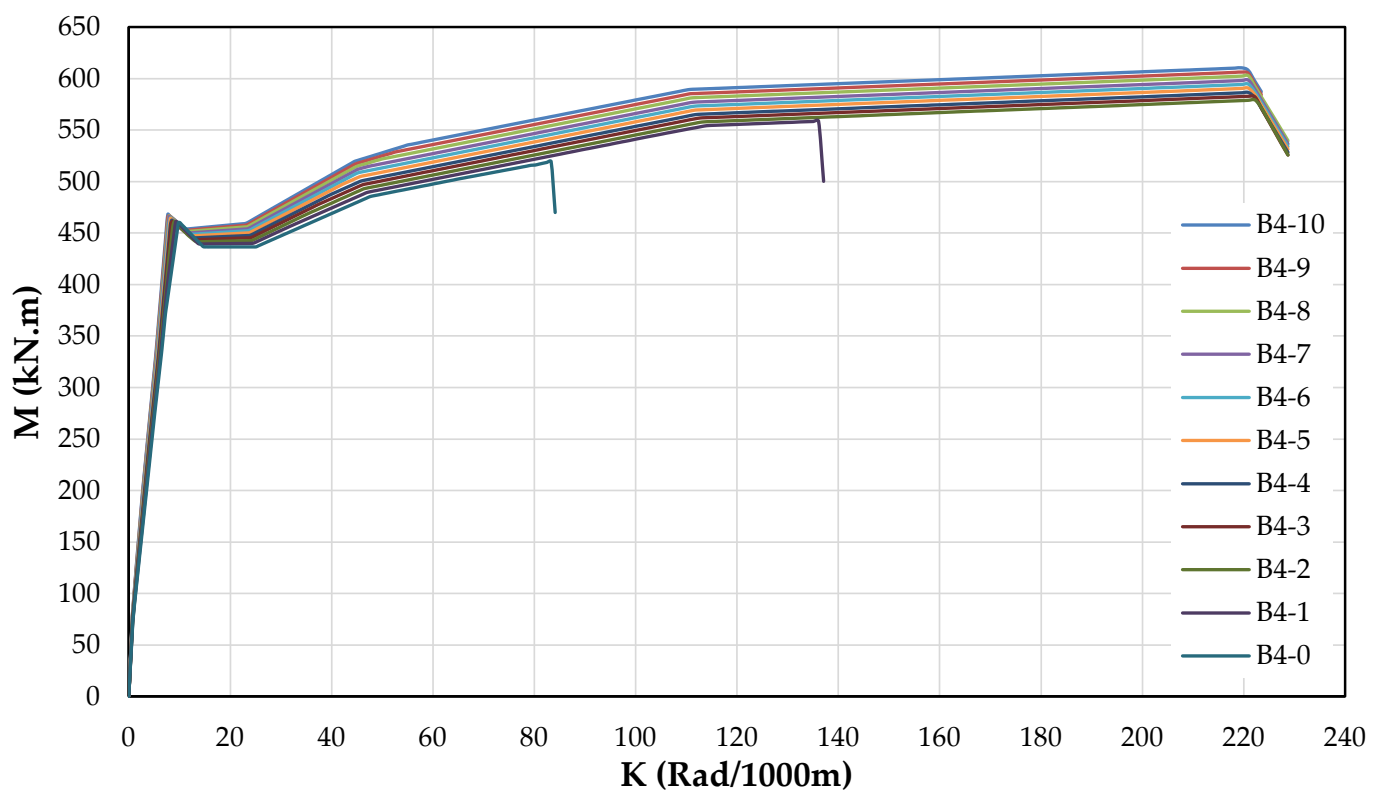

Şekil 5. Tip-4 olarak tasarlanan kiriş modellerine ait karşılaştırmalı moment eğrilik grafikleri.

Figure 5. Comparative moment curvature graphs of beam models designed as Type-4 


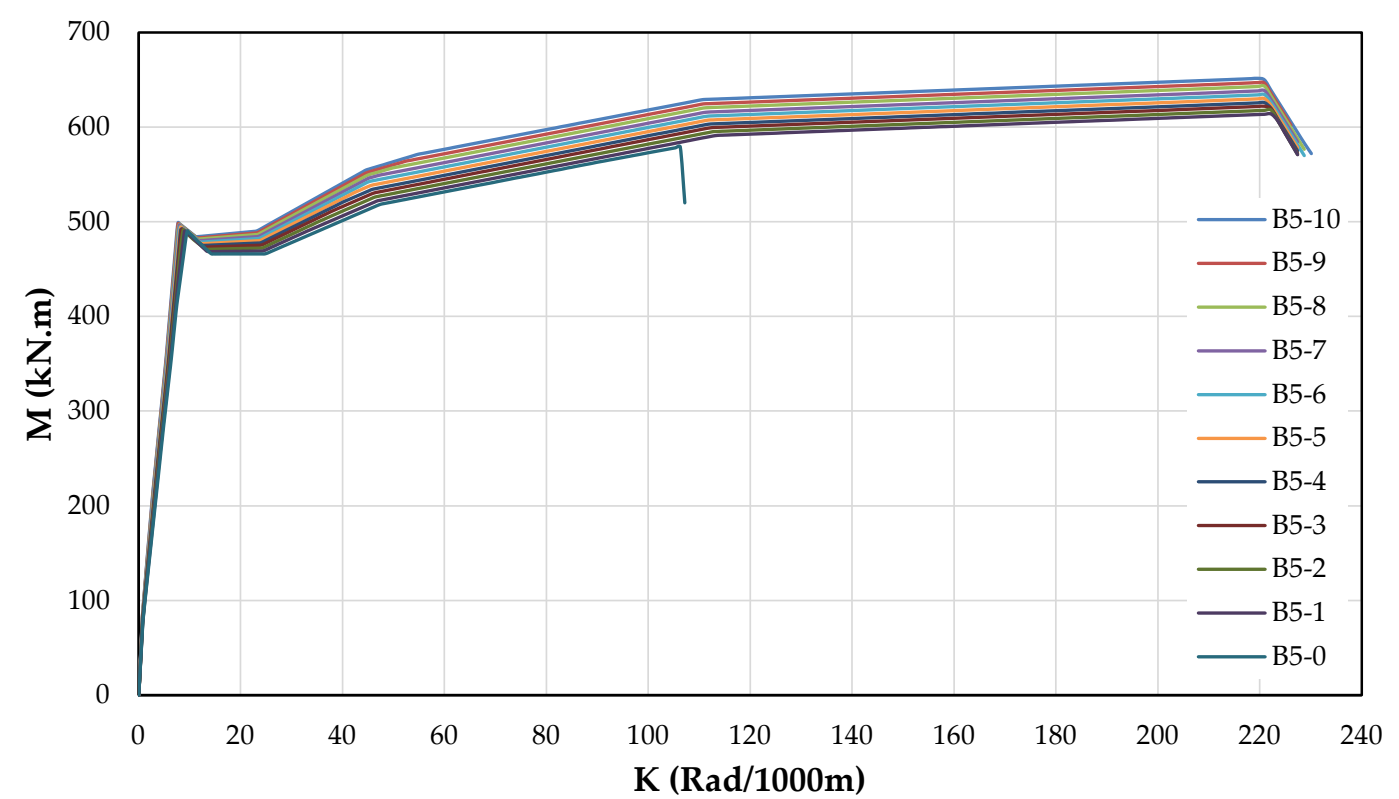

Şekil 6. Tip-5 olarak tasarlanan kiriş modellerine ait karşılaştırmalı moment eğrilik grafikleri. Figure 6. Comparative moment curvature graphs of beam models designed as Type-5

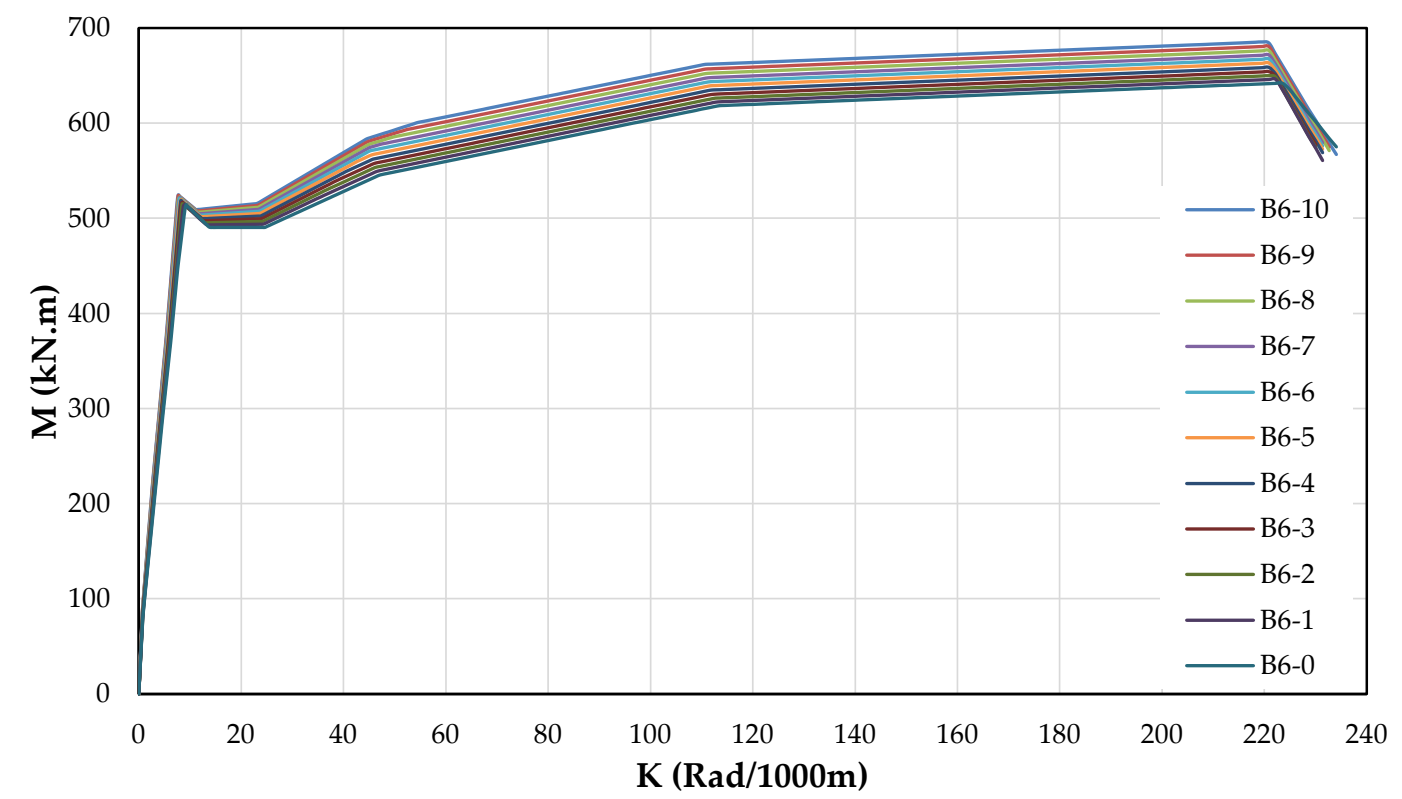

Şekil 7. Tip-6 olarak tasarlanan kiriş modellerine ait karşılaştırmalı moment eğrilik grafikleri.

Figure 7. Comparative moment curvature graphs of beam models designed as Type-6

Betonarme kiriş kesitlerinin moment-eğrilik ilişkilerinden kesitte oluşan hasar bölgelerinin sınırları farklı parametreler için irdelenmiştir. Betonarme kiriş kesitlerinde akma ve kırılma durumları için moment $\left(M_{y}, M_{u}\right)$ ve eğrilik $\left(K_{y}, K_{u}\right)$ değerleri, $M_{y i} / M_{y 1}$ oranları, $M_{u i} / M_{u 1}$ oranları, etkin eğilme rijitlikleri $\left(E I_{e}\right)$, etkin eğilme rijitlik oranları $\left(E I_{O}\right)$, eğrilik sünekliği $(\mu)$ ve eğrilik süneklik oranları $\left(\mu_{O}\right)$ Çizelge $(8$, 9, 10, 11, 12 ve 13)'te özetlenmiştir. Eğrilik sünekliği $(\mu)$ Denklem (4), etkin eğilme rijitlikleri $\left(E I_{e}\right)$ Denklem (5), etkin eğilme rijitlik oranları $\left(E I_{O}\right)$ Denklem (9), ve eğrilik süneklik oranları $\left(\mu_{O}\right)$ Denklem (10) ile hesaplanmıştır. Çizelgelerde moment $\left(M_{y}, M_{u}\right)$ değerleri; $k N m$, eğrilik $\left(K_{y}, K_{u}\right)$ değerleri $R a d \times$ $10^{3} / m$ ve Etkin eğilme rijitliği $\left(E I_{e}\right) ; k N \cdot m^{2}$ olarak verilmiştir. 
Çizelge 8. Tip-1 olarak tasarlanan kiriş modellerine ait analiz sonuçları.

Table 8. Analysis results of beam models designed as type-1

\begin{tabular}{|c|cccccccccc|}
\hline $\begin{array}{c}\text { Kesit } \\
\text { No }\end{array}$ & $\begin{array}{c}M_{y} \\
(\mathrm{kN} . \mathrm{m})\end{array}$ & $\begin{array}{c}K_{y} \\
(\mathrm{Rad} / \mathrm{km})\end{array}$ & $M_{y i} / M_{y 1}$ & $\begin{array}{c}M_{u} \\
(\mathrm{kN} . \mathrm{m})\end{array}$ & $\begin{array}{c}K_{u} \\
(\mathrm{Rad} / \mathrm{km})\end{array}$ & $M_{u i} / M_{u 1}$ & $E I_{e}$ & $E I_{O}$ & $\mu$ & $\mu_{o}$ \\
\hline B1-0 & 312.2 & 10.3 & 1.00 & 324.0 & 38.4 & 1.00 & 30.3 & 1.00 & 3.7 & 1.0 \\
B1-1 & 324.9 & 10.0 & 1.04 & 355.1 & 65.2 & 1.10 & 32.5 & 1.07 & 6.5 & 1.8 \\
B1-2 & 325.6 & 9.4 & 1.04 & 388.0 & 109.0 & 1.20 & 34.7 & 1.14 & 11.6 & 3.1 \\
B1-3 & 326.0 & 8.8 & 1.04 & 409.6 & 222.2 & 1.26 & 37.0 & 1.22 & 25.2 & 6.8 \\
B1-4 & 326.5 & 8.4 & 1.05 & 412.2 & 222.2 & 1.27 & 38.7 & 1.28 & 26.4 & 7.1 \\
B1-5 & 326.5 & 8.3 & 1.05 & 415.0 & 222.2 & 1.28 & 39.6 & 1.30 & 26.9 & 7.2 \\
B1-6 & 326.7 & 8.1 & 1.05 & 417.8 & 222.2 & 1.29 & 40.3 & 1.33 & 27.4 & 7.4 \\
B1-7 & 327.1 & 8.0 & 1.05 & 419.8 & 222.2 & 1.30 & 40.9 & 1.35 & 27.8 & 7.5 \\
B1-8 & 328.1 & 7.9 & 1.05 & 423.2 & 222.2 & 1.31 & 41.7 & 1.38 & 28.2 & 7.6 \\
B1-9 & 328.3 & 7.8 & 1.05 & 426.1 & 222.2 & 1.32 & 42.3 & 1.39 & 28.6 & 7.7 \\
B1-10 & 329.1 & 7.7 & 1.05 & 428.9 & 222.2 & 1.32 & 42.9 & 1.41 & 29.0 & 7.8 \\
\hline
\end{tabular}

Çizelge 9. Tip-2 olarak tasarlanan kiriş modellerine ait analiz sonuçları.

Table 9. Analysis results of beam models designed as type-2

\begin{tabular}{|c|cccccccccc|}
\hline $\begin{array}{c}\text { Kesit } \\
\text { No }\end{array}$ & $\begin{array}{c}M_{y} \\
(\mathrm{kN}, \mathrm{m})\end{array}$ & $\begin{array}{c}K_{y} \\
(\mathrm{Rad} / \mathrm{km})\end{array}$ & $M_{y i} / M_{y 1}$ & $\begin{array}{c}M_{u} \\
(\mathrm{kN}, \mathrm{m})\end{array}$ & $\begin{array}{c}K_{u} \\
(\mathrm{Rad} / \mathrm{km})\end{array}$ & $M_{u i} / M_{u 1}$ & $E I_{e}$ & $E I_{O}$ & $\mu$ & $\mu_{o}$ \\
\hline B2-0 & 362.3 & 10.1 & 1.00 & 366.8 & 58.0 & 1.00 & 35.9 & 1.00 & 5.7 & 1.0 \\
B2-1 & 367.5 & 9.6 & 1.01 & 425.1 & 93.2 & 1.16 & 38.2 & 1.06 & 9.7 & 1.7 \\
B2-2 & 367.6 & 9.0 & 1.01 & 462.0 & 222.2 & 1.26 & 40.7 & 1.13 & 24.6 & 4.3 \\
B2-3 & 368.6 & 8.6 & 1.02 & 465.1 & 222.2 & 1.27 & 43.0 & 1.20 & 25.9 & 4.5 \\
B2-4 & 368.7 & 8.3 & 1.02 & 468.1 & 222.2 & 1.28 & 44.3 & 1.24 & 26.7 & 4.7 \\
B2-5 & 369.1 & 8.2 & 1.02 & 471.2 & 222.2 & 1.28 & 45.0 & 1.25 & 27.1 & 4.7 \\
B2-6 & 370.3 & 8.1 & 1.02 & 474.3 & 222.2 & 1.29 & 46.0 & 1.28 & 27.6 & 4.8 \\
B2-7 & 371.0 & 8.0 & 1.02 & 477.0 & 222.2 & 1.30 & 46.6 & 1.30 & 27.9 & 4.9 \\
B2-8 & 372.0 & 7.8 & 1.03 & 478.9 & 222.2 & 1.31 & 47.5 & 1.32 & 28.4 & 4.9 \\
B2-9 & 372.7 & 7.7 & 1.03 & 480.8 & 222.2 & 1.31 & 48.1 & 1.34 & 28.7 & 5.0 \\
B2-10 & 373.0 & 7.6 & 1.03 & 487.0 & 222.2 & 1.33 & 48.8 & 1.36 & 29.1 & 5.1 \\
\hline
\end{tabular}


Çizelge 10. Tip-3 olarak tasarlanan kiriş modellerine ait analiz sonuçları.

Table 10. Analysis results of beam models designed as type-3

\begin{tabular}{|c|cccccccccc|}
\hline $\begin{array}{c}\text { Kesit } \\
\text { No }\end{array}$ & $\begin{array}{c}\mid c \\
M_{y} \\
(\mathrm{kN}, \mathrm{m})\end{array}$ & $\begin{array}{c}K_{y} \\
(\mathrm{Rad} / \mathrm{km})\end{array}$ & $M_{y i} / M_{y 1}$ & $\begin{array}{c}M_{u} \\
(\mathrm{kN}, \mathrm{m})\end{array}$ & $\begin{array}{c}K_{u} \\
(\mathrm{Rad} / \mathrm{km})\end{array}$ & $M_{u i} / M_{u 1}$ & $E I_{e}$ & $E I_{O}$ & $\mu$ & $\mu_{o}$ \\
\hline B3-0 & 406.7 & 9.9 & 1.00 & 454.2 & 77.03 & 1.00 & 41.2 & 1.00 & 7.8 & 1.0 \\
B3-1 & 406.8 & 9.3 & 1.00 & 490.4 & 114.5 & 1.08 & 43.8 & 1.06 & 12.3 & 1.6 \\
B3-2 & 407.8 & 8.8 & 1.00 & 512.5 & 222.2 & 1.13 & 46.4 & 1.13 & 25.3 & 3.2 \\
B3-3 & 408.0 & 8.5 & 1.00 & 515.7 & 222.2 & 1.14 & 48.2 & 1.17 & 26.3 & 3.4 \\
B3-4 & 408.4 & 8.3 & 1.00 & 519.2 & 222.2 & 1.14 & 49.4 & 1.20 & 26.9 & 3.5 \\
B3-5 & 409.3 & 8.1 & 1.01 & 522.7 & 222.2 & 1.15 & 50.3 & 1.22 & 27.3 & 3.5 \\
B3-6 & 409.5 & 8.0 & 1.01 & 526.2 & 222.2 & 1.16 & 51.1 & 1.24 & 27.7 & 3.6 \\
B3-7 & 410.2 & 7.9 & 1.01 & 529.6 & 222.2 & 1.17 & 51.9 & 1.26 & 28.1 & 3.6 \\
B3-8 & 410.7 & 7.8 & 1.01 & 533.0 & 222.2 & 1.17 & 52.6 & 1.28 & 28.5 & 3.7 \\
B3-9 & 411.5 & 7.7 & 1.01 & 536.6 & 222.2 & 1.18 & 53.3 & 1.29 & 28.8 & 3.7 \\
B3-10 & 414.2 & 7.6 & 1.02 & 540.3 & 222.2 & 1.19 & 54.3 & 1.32 & 29.2 & 3.7 \\
\hline
\end{tabular}

Çizelge 11. Tip-4 olarak tasarlanan kiriş modellerine ait analiz sonuçları. Table 11. Analysis results of beam models designed as type-4

\begin{tabular}{|c|ccccccccccc|}
\hline $\begin{array}{c}\text { Kesit } \\
\text { No }\end{array}$ & $\begin{array}{c}M_{y} \\
(\mathrm{kN}, \mathrm{m})\end{array}$ & $\begin{array}{c}K_{y} \\
(\mathrm{Rad} / \mathrm{km})\end{array}$ & $M_{y i} / M_{y 1}$ & $\begin{array}{c}M_{u} \\
(\mathrm{kN}, \mathrm{m})\end{array}$ & $\begin{array}{c}K_{u} \\
(\mathrm{Rad} / \mathrm{km})\end{array}$ & $M_{u i} / M_{u 1}$ & $E I_{e}$ & $E I_{O}$ & $\mu$ & $\mu_{o}$ \\
\hline B4-0 & 458.3 & 9.8 & 1.00 & 519.4 & 83.3 & 1.00 & 46.7 & 1.00 & 8.5 & 1.0 \\
B4-1 & 459.2 & 9.3 & 1.00 & 558.4 & 136.1 & 1.07 & 49.6 & 1.06 & 14.7 & 1.7 \\
B4-2 & 460.1 & 8.8 & 1.00 & 579.1 & 222.2 & 1.11 & 52.3 & 1.12 & 25.3 & 3.0 \\
B4-3 & 460.7 & 8.5 & 1.01 & 582.7 & 222.2 & 1.12 & 54.3 & 1.16 & 26.2 & 3.1 \\
B4-4 & 460.7 & 8.3 & 1.01 & 586.6 & 222.2 & 1.13 & 55.6 & 1.19 & 26.8 & 3.2 \\
B4-5 & 461.2 & 8.2 & 1.01 & 590.5 & 222.2 & 1.14 & 56.4 & 1.21 & 27.2 & 3.2 \\
B4-6 & 461.9 & 8.0 & 1.01 & 594.4 & 222.2 & 1.14 & 57.4 & 1.23 & 27.6 & 3.3 \\
B4-7 & 462.5 & 7.9 & 1.01 & 598.4 & 222.2 & 1.15 & 58.2 & 1.25 & 28.0 & 3.3 \\
B4-8 & 465.0 & 7.8 & 1.01 & 602.4 & 222.2 & 1.16 & 59.4 & 1.27 & 28.4 & 3.3 \\
B4-9 & 465.2 & 7.7 & 1.02 & 605.2 & 222.2 & 1.17 & 60.0 & 1.28 & 28.7 & 3.4 \\
B4-10 & 465.7 & 7.7 & 1.02 & 610.4 & 222.2 & 1.18 & 60.8 & 1.30 & 29.0 & 3.4 \\
\hline
\end{tabular}


Çizelge 12. Tip-5 olarak tasarlanan kiriş modellerine ait analiz sonuçları.

Table 12. Analysis results of beam models designed as type-5

\begin{tabular}{|c|cccccccccc|}
\hline $\begin{array}{c}\text { Kesit } \\
\text { No }\end{array}$ & $\begin{array}{c}M_{y} \\
(\mathrm{kN}, \mathrm{m})\end{array}$ & $\begin{array}{c}K_{y} \\
(\mathrm{Rad} / \mathrm{km})\end{array}$ & $M_{y i} / M_{y 1}$ & $\begin{array}{c}M_{u} \\
(\mathrm{kN}, \mathrm{m})\end{array}$ & $\begin{array}{c}K_{u} \\
(\mathrm{Rad} / \mathrm{km})\end{array}$ & $M_{u i} / M_{u 1}$ & $E I_{e}$ & $E I_{O}$ & $\mu$ & $\mu_{o}$ \\
\hline B5-0 & 486.9 & 9.4 & 1.00 & 579.1 & 106.3 & 1.00 & 51.8 & 1.00 & 11.3 & 1.0 \\
B5-1 & 488.0 & 9.0 & 1.00 & 614.1 & 222.2 & 1.06 & 54.2 & 1.05 & 24.7 & 2.2 \\
B5-2 & 488.1 & 8.6 & 1.00 & 618.2 & 222.2 & 1.07 & 56.6 & 1.09 & 25.8 & 2.3 \\
B5-3 & 490.2 & 8.4 & 1.01 & 622.0 & 222.2 & 1.07 & 58.6 & 1.13 & 26.6 & 2.4 \\
B5-4 & 490.4 & 8.2 & 1.01 & 626.1 & 222.2 & 1.08 & 59.5 & 1.15 & 27.0 & 2.4 \\
B5-5 & 491.5 & 8.1 & 1.01 & 630.2 & 222.2 & 1.09 & 60.6 & 1.17 & 27.4 & 2.4 \\
B5-6 & 493.1 & 8.0 & 1.01 & 634.5 & 222.2 & 1.10 & 61.6 & 1.19 & 27.8 & 2.5 \\
B5-7 & 493.5 & 7.9 & 1.01 & 638.7 & 222.2 & 1.10 & 62.5 & 1.21 & 28.1 & 2.5 \\
B5-8 & 493.5 & 7.8 & 1.01 & 643.0 & 222.2 & 1.11 & 63.3 & 1.22 & 28.5 & 2.5 \\
B5-9 & 495.2 & 7.7 & 1.02 & 647.1 & 222.2 & 1.12 & 64.1 & 1.24 & 28.8 & 2.5 \\
B5-10 & 498.1 & 7.6 & 1.02 & 651.5 & 222.2 & 1.13 & 65.3 & 1.26 & 29.1 & 2.6 \\
\hline
\end{tabular}

Çizelge 13. Tip-6 olarak tasarlanan kiriş modellerine ait analiz sonuçları. Table 13. Analysis results of beam models designed as type-6

\begin{tabular}{|c|cccccccccc|}
\hline $\begin{array}{c}\text { Kesit } \\
\text { No }\end{array}$ & $\begin{array}{c}M_{y} \\
(\mathrm{kN}, \mathrm{m})\end{array}$ & $\begin{array}{c}K_{y} \\
(\mathrm{Rad} / \mathrm{km})\end{array}$ & $M_{y i} / M_{y 1}$ & $\begin{array}{c}M_{u} \\
(\mathrm{kN}, \mathrm{m})\end{array}$ & $\begin{array}{c}K_{u} \\
(\mathrm{Rad} / \mathrm{km})\end{array}$ & $M_{u i} / M_{u 1}$ & $E I_{e}$ & $E I_{O}$ & $\mu$ & $\mu_{o}$ \\
\hline B6-0 & 510.3 & 9.1 & 1.00 & 642.0 & 222.2 & 1.00 & 56.1 & 1.00 & 24.4 & 1.0 \\
B6-1 & 512.9 & 8.8 & 1.01 & 646.0 & 222.2 & 1.01 & 58.6 & 1.04 & 25.4 & 1.1 \\
B6-2 & 513.0 & 8.5 & 1.01 & 650.1 & 222.2 & 1.01 & 60.5 & 1.08 & 26.2 & 1.1 \\
B6-3 & 515.0 & 8.3 & 1.01 & 654.3 & 222.2 & 1.02 & 62.1 & 1.11 & 26.8 & 1.1 \\
B6-4 & 515.3 & 8.2 & 1.01 & 658.6 & 222.2 & 1.03 & 63.0 & 1.12 & 27.1 & 1.1 \\
B6-5 & 516.9 & 8.1 & 1.01 & 663.0 & 222.2 & 1.03 & 64.2 & 1.14 & 27.6 & 1.1 \\
B6-6 & 517.5 & 8.0 & 1.01 & 667.4 & 222.2 & 1.04 & 64.9 & 1.16 & 27.9 & 1.1 \\
B6-7 & 519.8 & 7.9 & 1.02 & 671.9 & 222.2 & 1.05 & 66.2 & 1.18 & 28.3 & 1.2 \\
B6-8 & 520.1 & 7.8 & 1.02 & 676.4 & 222.2 & 1.05 & 66.9 & 1.19 & 28.6 & 1.2 \\
B6-9 & 520.7 & 7.7 & 1.02 & 680.7 & 222.2 & 1.06 & 67.7 & 1.21 & 28.9 & 1.2 \\
B6-10 & 522.2 & 7.6 & 1.02 & 684.3 & 222.2 & 1.07 & 68.7 & 1.22 & 29.2 & 1.2 \\
\hline
\end{tabular}

\section{ARAŞTIRMA SONUÇLARI ve TARTIŞMA (RESEARCH RESULTS AND DISCUSSION)}

Tasarlanan betonarme kiriş kesitlerinin farklı parametrelere göre analiz ve hesap sonuçlarından elde edilen değerler karşılaştırmalı olarak Çizelge 14, 15, 16, 17, 18 ve 19' da verilmiştir. Farklı parametrelere göre betonarme kiriş modellerinde moment-eğrilik analizlerinden elde edilen akma momenti değerleri Çizelge (14) ve akma eğrilik değerleri Çizelge (15)'te karşılaştırılmalı olarak verilmiştir. Farklı parametrelere göre betonarme kirişlerde moment-eğrilik analizlerinden elde edilen kırılma momenti değerleri Çizelge (16) ve kırılma anındaki eğrilik değerleri Çizelge (17)'de karşılaştırılmalı olarak verilmiştir. Betonarme kirişlerin moment-eğrilik ilişiklilerinden elde edilen $M_{y}$ ve $k_{y}$ değerlerine göre kesitlerin etkin eğilme rijitlik oranları $\left(E I_{o}\right)$ Çizelge (18) ve betonarme kirişlerinin eğrilik süneklik oranları $\left(\mu_{o}\right)$ Çizelge $(19)^{\prime}$ da karşılaştırmalı olarak verilmiştir. Betonarme kiriş elemanlarının kesit geometrisi ve karakteristik basınç dayanımlarına göre Denklem (6 ve 7)'e göre kesitlerin çatlamamış eğilme rijitlikleri $(E I)$ hesaplanmış ve Çizelge (20)'de verilmiştir. Betonarme kirişlerin moment-eğrilik ilişkilerine göre Denklem (5) ile etkin rijitlik $\left(E I_{e}\right)$ değerleri ve Denklem (6 ve 7) ile hesaplanan çatlamamış kesitin eğilme rijitliklerine $(E I)$ göre hesaplanan etkin rijitlik çarpanları $\left(k_{e}\right)$ Çizelge (21)'de ve karşılaştırmalı grafiği Şekil (8)'de verilmiştir. 
Çizelge 14. Kiriş modellerinde analizlerden elde edilen akma momenti değerlerinin karşılaştırılması. Table 14. Comparison of yield moment values obtained from analysis results in beam models

\begin{tabular}{|c|ccccccccccc|}
\hline $\begin{array}{c}\text { Kesit } \\
\text { No }\end{array}$ & $M_{y}$ & $\begin{array}{c}\text { Kesit } \\
\text { No }\end{array}$ & $M_{y}$ & $\begin{array}{c}\text { Kesit } \\
\text { No }\end{array}$ & $M_{y}$ & $\begin{array}{c}\text { Kesit } \\
\text { No }\end{array}$ & $M_{y}$ & $\begin{array}{c}\text { Kesit } \\
\text { No }\end{array}$ & $M_{y}$ & $\begin{array}{c}\text { Kesit } \\
\text { No }\end{array}$ & $M_{y}$ \\
\hline B1-0 & 312.2 & B2-0 & 362.3 & B3-0 & 406.7 & B4-0 & 458.3 & B5-0 & 486.9 & B6-0 & 510.3 \\
B1-1 & 324.9 & B2-1 & 367.5 & B3-1 & 406.8 & B4-1 & 459.2 & B5-1 & 488.0 & B6-1 & 512.9 \\
B1-2 & 325.6 & B2-2 & 367.6 & B3-2 & 407.8 & B4-2 & 460.1 & B5-2 & 488.1 & B6-2 & 513.0 \\
B1-3 & 326.0 & B2-3 & 368.6 & B3-3 & 408.0 & B4-3 & 460.7 & B5-3 & 490.2 & B6-3 & 515.0 \\
B1-4 & 326.5 & B2-4 & 368.7 & B3-4 & 408.4 & B4-4 & 460.7 & B5-4 & 490.4 & B6-4 & 515.3 \\
B1-5 & 326.5 & B2-5 & 369.1 & B3-5 & 409.3 & B4-5 & 461.2 & B5-5 & 491.5 & B6-5 & 516.9 \\
B1-6 & 326.7 & B2-6 & 370.3 & B3-6 & 409.5 & B4-6 & 461.9 & B5-6 & 493.1 & B6-6 & 517.5 \\
B1-7 & 327.1 & B2-7 & 371.0 & B3-7 & 410.2 & B4-7 & 462.5 & B5-7 & 493.5 & B6-7 & 519.8 \\
B1-8 & 328.1 & B2-8 & 372.0 & B3-8 & 410.7 & B4-8 & 465.0 & B5-8 & 493.5 & B6-8 & 520.1 \\
B1-9 & 328.3 & B2-9 & 372.7 & B3-9 & 411.5 & B4-9 & 465.2 & B5-9 & 495.2 & B6-9 & 520.7 \\
B1-10 & 329.1 & B2-10 & 373.0 & B3-10 & 414.2 & B4-10 & 465.7 & B5-10 & 498.1 & B6-10 & 522.2 \\
\hline
\end{tabular}

Çizelge 15. Kiriş modellerinde analizlerden elde edilen akma eğriliği değerlerinin karşılaştırılması. Table 15. Comparison of yield curvature values obtained from analysis results in beam models

\begin{tabular}{|c|ccccccccccc|}
\hline $\begin{array}{c}\text { Kesit } \\
\text { No }\end{array}$ & $K_{y}$ & $\begin{array}{c}\text { Kesit } \\
\text { No }\end{array}$ & $K_{y}$ & $\begin{array}{c}\text { Kesit } \\
\text { No }\end{array}$ & $K_{y}$ & $\begin{array}{c}\text { Kesit } \\
\text { No }\end{array}$ & $K_{y}$ & $\begin{array}{c}\text { Kesit } \\
\text { No }\end{array}$ & $K_{y}$ & $\begin{array}{c}\text { Kesit } \\
\text { No }\end{array}$ & $K_{y}$ \\
\hline B1-0 & 10.3 & B2-0 & 10.1 & B3-0 & 9.9 & B4-0 & 9.8 & B5-0 & 9.4 & B6-0 & 9.1 \\
B1-1 & 10.0 & B2-1 & 9.6 & B3-1 & 9.3 & B4-1 & 9.3 & B5-1 & 9.0 & B6-1 & 8.8 \\
B1-2 & 9.4 & B2-2 & 9.0 & B3-2 & 8.8 & B4-2 & 8.8 & B5-2 & 8.6 & B6-2 & 8.5 \\
B1-3 & 8.8 & B2-3 & 8.6 & B3-3 & 8.5 & B4-3 & 8.5 & B5-3 & 8.4 & B6-3 & 8.3 \\
B1-4 & 8.4 & B2-4 & 8.3 & B3-4 & 8.3 & B4-4 & 8.3 & B5-4 & 8.2 & B6-4 & 8.2 \\
B1-5 & 8.3 & B2-5 & 8.2 & B3-5 & 8.1 & B4-5 & 8.2 & B5-5 & 8.1 & B6-5 & 8.1 \\
B1-6 & 8.1 & B2-6 & 8.1 & B3-6 & 8.0 & B4-6 & 8.0 & B5-6 & 8.0 & B6-6 & 8.0 \\
B1-7 & 8.0 & B2-7 & 8.0 & B3-7 & 7.9 & B4-7 & 7.9 & B5-7 & 7.9 & B6-7 & 7.9 \\
B1-8 & 7.9 & B2-8 & 7.8 & B3-8 & 7.8 & B4-8 & 7.8 & B5-8 & 7.8 & B6-8 & 7.8 \\
B1-9 & 7.8 & B2-9 & 7.7 & B3-9 & 7.7 & B4-9 & 7.7 & B5-9 & 7.7 & B6-9 & 7.7 \\
B1-10 & 7.7 & B2-10 & 7.6 & B3-10 & 7.6 & B4-10 & 7.7 & B5-10 & 7.6 & B6-10 & 7.6 \\
\hline
\end{tabular}

Çizelge 16. Kiriş modelleri analizlerden elde edilen maksimum momenti değerlerinin karşılaştırılması. Table 16. Comparison of ultimate moment values obtained from analysis results in beam models

\begin{tabular}{|c|ccccccccccc|}
\hline $\begin{array}{c}\text { Kesit } \\
\text { No }\end{array}$ & $M_{u}$ & $\begin{array}{c}\text { Kesit } \\
\text { No }\end{array}$ & $M_{u}$ & $\begin{array}{c}\text { Kesit } \\
\text { No }\end{array}$ & $M_{u}$ & $\begin{array}{c}\text { Kesit } \\
\text { No }\end{array}$ & $M_{u}$ & $\begin{array}{c}\text { Kesit } \\
\text { No }\end{array}$ & $M_{u}$ & $\begin{array}{c}\text { Kesit } \\
\text { No }\end{array}$ & $M_{u}$ \\
\hline B1-0 & 324.0 & B2-0 & 366.8 & B3-0 & 454.2 & B4-0 & 519.4 & B5-0 & 579.1 & B6-0 & 642.0 \\
B1-1 & 355.1 & B2-1 & 425.1 & B3-1 & 490.4 & B4-1 & 558.4 & B5-1 & 614.1 & B6-1 & 646.0 \\
B1-2 & 388.0 & B2-2 & 462.0 & B3-2 & 512.5 & B4-2 & 579.1 & B5-2 & 618.2 & B6-2 & 650.1 \\
B1-3 & 409.6 & B2-3 & 465.1 & B3-3 & 515.7 & B4-3 & 582.7 & B5-3 & 622.0 & B6-3 & 654.3 \\
B1-4 & 412.2 & B2-4 & 468.1 & B3-4 & 519.2 & B4-4 & 586.6 & B5-4 & 626.1 & B6-4 & 658.6 \\
B1-5 & 415.0 & B2-5 & 471.2 & B3-5 & 522.7 & B4-5 & 590.5 & B5-5 & 630.2 & B6-5 & 663.0 \\
B1-6 & 417.8 & B2-6 & 474.3 & B3-6 & 526.2 & B4-6 & 594.4 & B5-6 & 634.5 & B6-6 & 667.4 \\
B1-7 & 419.8 & B2-7 & 477.0 & B3-7 & 529.6 & B4-7 & 598.4 & B5-7 & 638.7 & B6-7 & 671.9 \\
B1-8 & 423.2 & B2-8 & 478.9 & B3-8 & 533.0 & B4-8 & 602.4 & B5-8 & 643.0 & B6-8 & 676.4 \\
B1-9 & 426.1 & B2-9 & 480.8 & B3-9 & 536.6 & B4-9 & 605.2 & B5-9 & 647.1 & B6-9 & 680.7 \\
B1-10 & 428.9 & B2-10 & 487.0 & B3-10 & 540.3 & B4-10 & 610.4 & B5-10 & 651.5 & B6-10 & 684.3 \\
\hline
\end{tabular}


Çizelge 17. Kiriş modelleri analizlerinden elde edilen maksimum eğrilik değerlerinin karşılaştırılması. Table 17. Comparison of ultimate curvature values obtained from analysis results in beam models

\begin{tabular}{|c|ccccccccccc|}
\hline $\begin{array}{c}\text { Kesit } \\
\text { No }\end{array}$ & $K_{u}$ & $\begin{array}{c}\text { Kesit } \\
\text { No }\end{array}$ & $K_{u}$ & $\begin{array}{c}\text { Kesit } \\
\text { No }\end{array}$ & $K_{u}$ & $\begin{array}{c}\text { Kesit } \\
\text { No }\end{array}$ & $K_{u}$ & $\begin{array}{c}\text { Kesit } \\
\text { No }\end{array}$ & $K_{u}$ & Kesit & \multirow{2}{*}{$K_{u}$} \\
\hline B1-0 & 38.4 & B2-0 & 58.0 & B3-0 & 77.0 & B4-0 & 83.3 & B5-0 & 106.3 & B6-0 & 222.2 \\
B1-1 & 65.2 & B2-1 & 93.2 & B3-1 & 114.5 & B4-1 & 136.1 & B5-1 & 222.2 & B6-1 & 222.2 \\
B1-2 & 109.0 & B2-2 & 222.2 & B3-2 & 222.2 & B4-2 & 222.2 & B5-2 & 222.2 & B6-2 & 222.2 \\
B1-3 & 222.2 & B2-3 & 222.2 & B3-3 & 222.2 & B4-3 & 222.2 & B5-3 & 222.2 & B6-3 & 222.2 \\
B1-4 & 222.2 & B2-4 & 222.2 & B3-4 & 222.2 & B4-4 & 222.2 & B5-4 & 222.2 & B6-4 & 222.2 \\
B1-5 & 222.2 & B2-5 & 222.2 & B3-5 & 222.2 & B4-5 & 222.2 & B5-5 & 222.2 & B6-5 & 222.2 \\
B1-6 & 222.2 & B2-6 & 222.2 & B3-6 & 222.2 & B4-6 & 222.2 & B5-6 & 222.2 & B6-6 & 222.2 \\
B1-7 & 222.2 & B2-7 & 222.2 & B3-7 & 222.2 & B4-7 & 222.2 & B5-7 & 222.2 & B6-7 & 222.2 \\
B1-8 & 222.2 & B2-8 & 222.2 & B3-8 & 222.2 & B4-8 & 222.2 & B5-8 & 222.2 & B6-8 & 222.2 \\
B1-9 & 222.2 & B2-9 & 222.2 & B3-9 & 222.2 & B4-9 & 222.2 & B5-9 & 222.2 & B6-9 & 222.2 \\
B1-10 & 222.2 & B2-10 & 222.2 & B3-10 & 222.2 & B4-10 & 222.2 & B5-10 & 222.2 & B6-10 & 222.2 \\
\hline
\end{tabular}

Çizelge 18. Kiriş modelleri analizlerinden elde edilen rijitlik oranlarının $\left(\mathrm{EI}_{\mathrm{o}}\right)$ karşılaştırılması.

Table 18. Comparison of stiffness ratios $\left(\mathrm{EI}_{\mathrm{o}}\right.$ ) obtained from beam model analysis

\begin{tabular}{|c|ccccccccccc|}
\hline $\begin{array}{c}\text { Kesit } \\
\text { No }\end{array}$ & $E I_{o}$ & $\begin{array}{c}\text { Kesit } \\
\text { No }\end{array}$ & $E I_{o}$ & $\begin{array}{c}\text { Kesit } \\
\text { No }\end{array}$ & $E I_{o}$ & $\begin{array}{c}\text { Kesit } \\
\text { No }\end{array}$ & $E I_{o}$ & $\begin{array}{c}\text { Kesit } \\
\text { No }\end{array}$ & $E I_{o}$ & $\begin{array}{c}\text { Kesit } \\
\text { No }\end{array}$ & $E I_{o}$ \\
\hline B1-0 & 1.00 & B2-0 & 1.00 & B3-0 & 1.00 & B4-0 & 1.00 & B5-0 & 1.00 & B6-0 & 1.00 \\
B1-1 & 1.07 & B2-1 & 1.06 & B3-1 & 1.06 & B4-1 & 1.06 & B5-1 & 1.05 & B6-1 & 1.04 \\
B1-2 & 1.14 & B2-2 & 1.13 & B3-2 & 1.13 & B4-2 & 1.12 & B5-2 & 1.09 & B6-2 & 1.08 \\
B1-3 & 1.22 & B2-3 & 1.20 & B3-3 & 1.17 & B4-3 & 1.16 & B5-3 & 1.13 & B6-3 & 1.11 \\
B1-4 & 1.28 & B2-4 & 1.24 & B3-4 & 1.20 & B4-4 & 1.19 & B5-4 & 1.15 & B6-4 & 1.12 \\
B1-5 & 1.30 & B2-5 & 1.25 & B3-5 & 1.22 & B4-5 & 1.21 & B5-5 & 1.17 & B6-5 & 1.14 \\
B1-6 & 1.33 & B2-6 & 1.28 & B3-6 & 1.24 & B4-6 & 1.23 & B5-6 & 1.19 & B6-6 & 1.16 \\
B1-7 & 1.35 & B2-7 & 1.30 & B3-7 & 1.26 & B4-7 & 1.25 & B5-7 & 1.21 & B6-7 & 1.18 \\
B1-8 & 1.38 & B2-8 & 1.32 & B3-8 & 1.28 & B4-8 & 1.27 & B5-8 & 1.22 & B6-8 & 1.19 \\
B1-9 & 1.39 & B2-9 & 1.34 & B3-9 & 1.29 & B4-9 & 1.28 & B5-9 & 1.24 & B6-9 & 1.21 \\
B1-10 & 1.41 & B2-10 & 1.36 & B3-10 & 1.32 & B4-10 & 1.30 & B5-10 & 1.26 & B6-10 & 1.22 \\
\hline
\end{tabular}

Çizelge 19. Kiriş modelleri analizlerinden elde edilen süneklik oranlarının $\left(\mu_{\mathrm{o}}\right)$ karşılaştırılması.

Table 19. Comparison of ductility ratios $\left(\mu_{0}\right)$ obtained from beam model analysis

\begin{tabular}{|c|ccccccccccc|}
\hline Kesit No & $\mu_{o}$ & Kesit No & $\mu_{o}$ & Kesit No & $\mu_{o}$ & Kesit No & $\mu_{o}$ & Kesit No & $\mu_{o}$ & Kesit No & $\mu_{o}$ \\
\hline B1-0 & 1.0 & B2-0 & 1.0 & B3-0 & 1.0 & B4-0 & 1.0 & B5-0 & 1.0 & B6-0 & 1.0 \\
B1-1 & 1.8 & B2-1 & 1.7 & B3-1 & 1.6 & B4-1 & 1.7 & B5-1 & 2.2 & B6-1 & 1.0 \\
B1-2 & 3.1 & B2-2 & 4.3 & B3-2 & 3.2 & B4-2 & 3.0 & B5-2 & 2.3 & B6-2 & 1.1 \\
B1-3 & 6.8 & B2-3 & 4.5 & B3-3 & 3.4 & B4-3 & 3.1 & B5-3 & 2.4 & B6-3 & 1.1 \\
B1-4 & 7.1 & B2-4 & 4.7 & B3-4 & 3.5 & B4-4 & 3.2 & B5-4 & 2.4 & B6-4 & 1.1 \\
B1-5 & 7.2 & B2-5 & 4.7 & B3-5 & 3.5 & B4-5 & 3.2 & B5-5 & 2.4 & B6-5 & 1.1 \\
B1-6 & 7.4 & B2-6 & 4.8 & B3-6 & 3.6 & B4-6 & 3.3 & B5-6 & 2.5 & B6-6 & 1.1 \\
B1-7 & 7.5 & B2-7 & 4.9 & B3-7 & 3.6 & B4-7 & 3.3 & B5-7 & 2.5 & B6-7 & 1.2 \\
B1-8 & 7.6 & B2-8 & 4.9 & B3-8 & 3.7 & B4-8 & 3.3 & B5-8 & 2.5 & B6-8 & 1.2 \\
B1-9 & 7.7 & B2-9 & 5.0 & B3-9 & 3.7 & B4-9 & 3.4 & B5-9 & 2.5 & B6-9 & 1.2 \\
B1-10 & 7.8 & B2-10 & 5.1 & B3-10 & 3.7 & B4-10 & 3.4 & B5-10 & 2.6 & B6-10 & 1.2 \\
\hline
\end{tabular}


Çizelge 20. Betonarme kiriş elemanlarının çatlamamış eğilme rijitliği (EI). Table 20. flexural bending stiffness (EI) of reinforced concrete beam elements

\begin{tabular}{|c|ccccc|}
\hline $\begin{array}{c}\text { Beton } \\
\text { Sinifi }\end{array}$ & $\mathrm{E}_{\mathrm{c}}(\mathrm{MPa})$ & $\begin{array}{c}\mathrm{b} \\
(\mathrm{m})\end{array}$ & $\begin{array}{c}\mathrm{h} \\
(\mathrm{m})\end{array}$ & $\begin{array}{c}\mathrm{I} \\
\left(\mathrm{m}^{4}\right)\end{array}$ & $\begin{array}{c}E I \\
\left(\mathrm{kNxm}^{2}\right)\end{array}$ \\
\hline 25 & 30250.0 & 0.25 & 0.5 & 0.0026042 & 88776.04 \\
30 & 31801.0 & 0.25 & 0.5 & 0.0026042 & 92815.06 \\
35 & 33227.3 & 0.25 & 0.5 & 0.0026042 & 96529.32 \\
40 & 34554.8 & 0.25 & 0.5 & 0.0026042 & 99986.47 \\
45 & 35801.7 & 0.25 & 0.5 & 0.0026042 & 103233.50 \\
50 & 36981.0 & 0.25 & 0.5 & 0.0026042 & 106304.61 \\
\hline
\end{tabular}

Çizelge 21. Betonarme kiriş elemanlarının etkin rijitlik katsayıları $\left(k_{e}\right)$. Table 21. effective stiffness coefficients $\left(k_{e}\right)$ of reinforced concrete beam elements

\begin{tabular}{|c|cccccccccccc|}
\hline$\rho^{\prime}$ & $\begin{array}{c}\text { Kesit } \\
\text { No }\end{array}$ & $k_{e}$ & $\begin{array}{c}\text { Kesit } \\
\text { No }\end{array}$ & $k_{e}$ & $\begin{array}{c}\text { Kesit } \\
\text { No }\end{array}$ & $k_{e}$ & $\begin{array}{c}\text { Kesit } \\
\text { No }\end{array}$ & $k_{e}$ & $\begin{array}{c}\text { Kesit } \\
\text { No }\end{array}$ & $k_{e}$ & $\begin{array}{c}\text { Kesit } \\
\text { No }\end{array}$ & $k_{e}$ \\
\hline 0 & B1-0 & 0.34 & B2-0 & 0.39 & B3-0 & 0.43 & B4-0 & 0.47 & B5-0 & 0.50 & B6-0 & 0.53 \\
0,1 & B1-1 & 0.37 & B2-1 & 0.41 & B3-1 & 0.45 & B4-1 & 0.50 & B5-1 & 0.53 & B6-1 & 0.55 \\
0,2 & B1-2 & 0.39 & B2-2 & 0.44 & B3-2 & 0.48 & B4-2 & 0.52 & B5-2 & 0.55 & B6-2 & 0.57 \\
0,3 & B1-3 & 0.42 & B2-3 & 0.46 & B3-3 & 0.50 & B4-3 & 0.54 & B5-3 & 0.57 & B6-3 & 0.58 \\
0,4 & B1-4 & 0.44 & B2-4 & 0.48 & B3-4 & 0.51 & B4-4 & 0.56 & B5-4 & 0.58 & B6-4 & 0.59 \\
0,5 & B1-5 & 0.45 & B2-5 & 0.48 & B3-5 & 0.52 & B4-5 & 0.56 & B5-5 & 0.59 & B6-5 & 0.60 \\
0,6 & B1-6 & 0.45 & B2-6 & 0.50 & B3-6 & 0.53 & B4-6 & 0.57 & B5-6 & 0.60 & B6-6 & 0.61 \\
0,7 & B1-7 & 0.46 & B2-7 & 0.50 & B3-7 & 0.54 & B4-7 & 0.58 & B5-7 & 0.61 & B6-7 & 0.62 \\
0,8 & B1-8 & 0.47 & B2-8 & 0.51 & B3-8 & 0.55 & B4-8 & 0.59 & B5-8 & 0.61 & B6-8 & 0.63 \\
0,9 & B1-9 & 0.48 & B2-9 & 0.52 & B3-9 & 0.55 & B4-9 & 0.60 & B5-9 & 0.62 & B6-9 & 0.64 \\
1 & B1-10 & 0.48 & B2-10 & 0.53 & B3-10 & 0.56 & B4-10 & 0.61 & B5-10 & 0.63 & B6-10 & 0.65 \\
\hline \multicolumn{10}{l}{$\mathrm{k}_{\mathrm{e}} ;$ Betonarme Taş1y1C1 Sistem Elemanlarinin Etkin Kesit Rijitlik Katsay1S1 } & & & \\
\hline
\end{tabular}

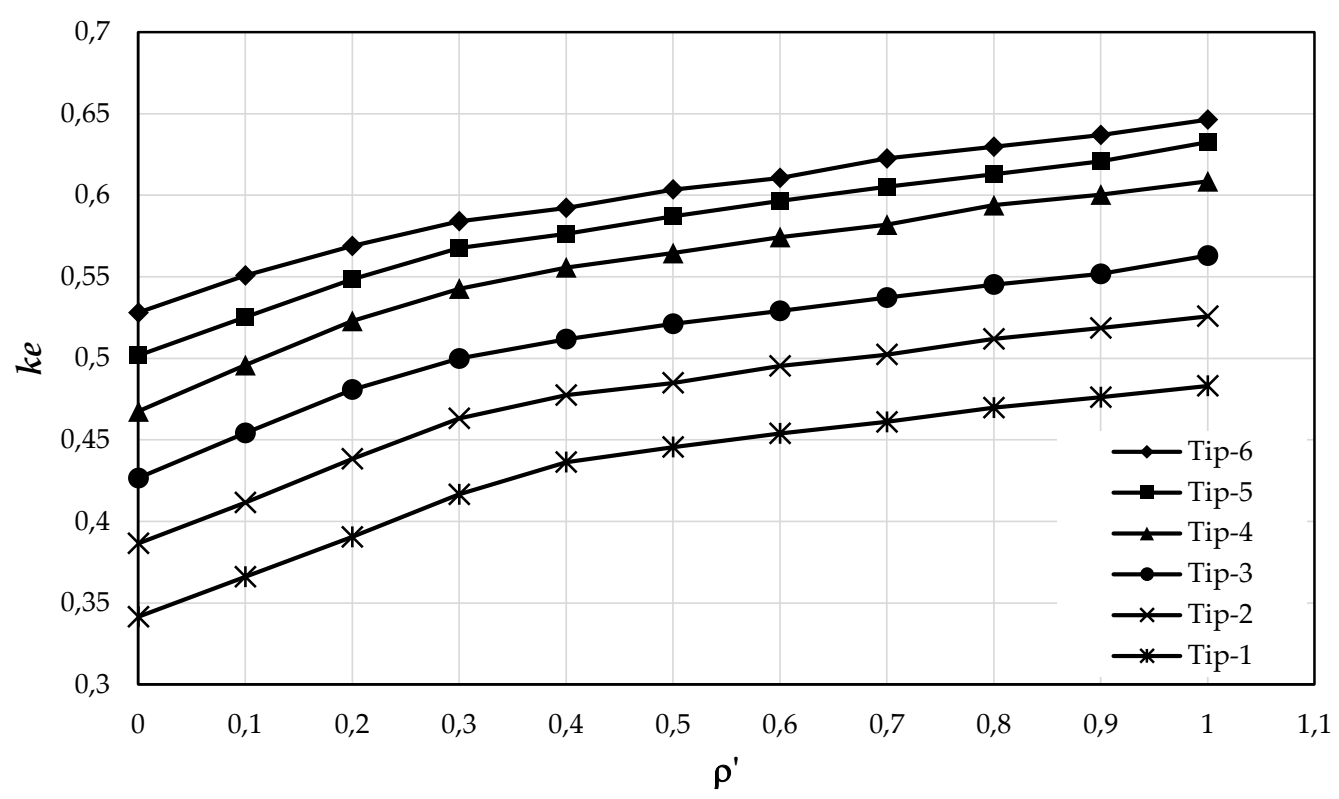

Şekil 8. Betonarme kiriş elemanlarının farklı tip modellerine göre etkin eğilme rijitlik çarpanlarının karşılaştırılmalı grafiği.

Figure 8. Comparison curves of effective stiffness coefficients according to different types of reinforced concrete beam elements 


\section{SONUÇ (DISCUSSIONS)}

Araştırma Sonuçları ve Tartışma bölümünde özetlenen sonuçların ışığında aşağıdaki sonuçlar elde edilmiştir.

- Betonarme kirişlerde sabit beton basınç dayanımı ve çekme donatısı oranı için basınç donatısı oranının artması ile moment-eğrilik ilişkilerinden elde edilen $M_{y}, M_{u}$ ve $k_{u}$ değerleri artmakta fakat $k_{y}$ değerleri azalmaktadır. Basınç donatı oranının artması ile kesitlerin maksimum moment taşıma kapasitesi ve sünekliği artmaktadır.

- Sabit basınç donatısı ve çekme donatısı oranına sahip betonarme kirişlerde beton basınç dayanımının artması ile $M_{y}$ ve $M_{u}$ değerleri artmakta, $k_{y}$ ve $k_{u}$ değerleri; $\rho^{\prime}=0.40 \rho$ oranına kadar azalmakta ve $\rho^{\prime}=0.50 \rho$ oranından $\rho^{\prime}=\rho$ oranına kadar sabit kalmaktadır. Beton basınç dayanımının artması maksimum moment kapasitesini artırmaktadır.

- Betonarme kirişlerde sabit beton basınç dayanımı ve çekme donatısı oranı için basınç donatısı oranının artması ile moment-eğrilik ilişkilerinden elde edilen $E I_{o}$ değerleri artmaktadır. Basınç donatısı oranının artması ile kesitlerin eğilme rijitliği artmaktadır.

- Sabit basınç donatısı ve çekme donatısı oranına sahip betonarme kirişlerde beton basınç dayanımının artması ile hesaplanan $E I_{o}$ değerleri azalmaktadır.

- Betonarme kirişlerde sabit beton basınç dayanımı ve çekme donatısı oranı için basınç donatı oranının artması ile moment-eğrilik ilişkilerinden elde edilen değerlere göre hesaplanan $\mu_{o}$ değerleri artmaktadir.

- Sabit basınç donatısı ve çekme donatısı oranına sahip betonarme kirişlerde beton basınç dayanımının artması ile $\mu_{o}$ değerleri; $\rho^{\prime}=0.40 \rho$ oranına kadar artmakta ve $\rho^{\prime}=0.50 \rho$ oranından $\rho^{\prime}=\rho$ oranına kadar azalmaktadır.

- Betonarme kirişlerde sabit beton basınç dayanımı ve çekme donatısı oranı için, basınç donatı oranının artması ile $k_{e}$ değerleri artmaktadır.

- Sabit basınç donatısı ve çekme donatısı oranına sahip betonarme kirişlerde beton basınç dayanımının artması ile $k_{e}$ değerleri artmaktadır.

- Basınç donatısı oranının betonarme kirişlerin maksimum moment taşıma kapasitesi, etkin eğilme rijitliği, sünekliği ve kesitlerin etkin eğilme rijitlileri üzerinde etkili olduğu ispatlanmıştır.

\section{KAYNAKLAR (REFERENCES)}

Canbay, E., Ersoy, U., Özcebe, G., Sucuoğlu, H., Wasti, S. T., 2010. Binalar İçin Deprem Mühendisliği Temel Ilkeler, ISBN: 9799789944070, ODTÜ, Akademik Kitaplar Yayınevi, Ankara.

Çağlar, N., Akkaya, A., Demir, A., Öztürk, H., 2004. Farklı Kesit Geometrilerine Sahip Betonarme Kolonların Davranışının İncelenmesi, ISITES2014, p. 2095-2105, Karabük/Türkiye.

Ersoy, U., Özcebe, G., 2012, Betonarme 1, İSBN: 978-975-503-215-31, Evrim Yayınevi ve Bilgisayar San. Tic. Ltd. Şti, İstanbul.

Mander, J. B., Priestley, M. J. N., Park, R., 1988a. "Theoretical stress-strain model for confined concrete“, Journal of Structural Engineering, Vol. 114, No. 8, pp.1804-1826.

SAP2000, Structural Software for Analysis and Design, Computers and Structures, Inc, Version 20.2.0.0 USA.

TBDY, 2018, Türkiye Bina Deprem Yönetmeliği, T.C. Bayındırlık ve İskân Bakanlığı, Ankara.

TS500, 2000, Betonarme Yapıların Tasarım ve Yapım Kuralları, Türk Standardları Enstitüsü, TSE, Ankara. 